\title{
Photochemical Modification of Carbene-Based Metallacycles: A Facile Route to Polycarbene Complexes and Their Derivatives
}

Chun-Xiang Wang, Yang Gao, Yu-Xin Deng, Yue-Jian Lin, Ying-Feng Han,* and Guo-Xin Jin*

Collaborative Innovation Center of Chemistry for Energy Materials

Department of Chemistry, Fudan University, 220 Handan Road, 200433 Shanghai, P. R. China 


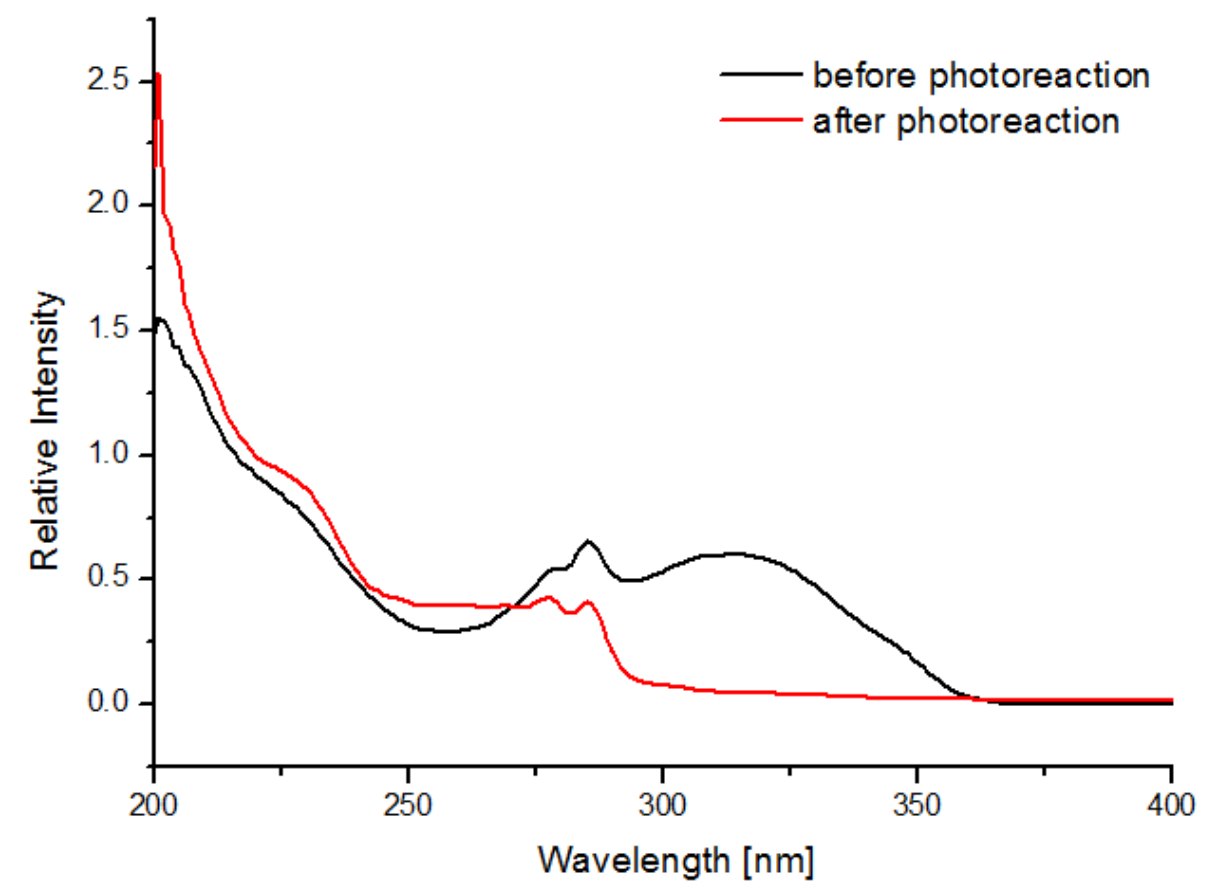

Figure S1. UV-Vis spectra of $\left[\mathrm{Ag}_{2}(\mathbf{1})_{2}\right]\left(\mathrm{PF}_{6}\right)_{2}(5 \mu \mathrm{M})$ in $\mathrm{CH}_{3} \mathrm{CN}$ before (dark line) and after (red line) photoreaction.

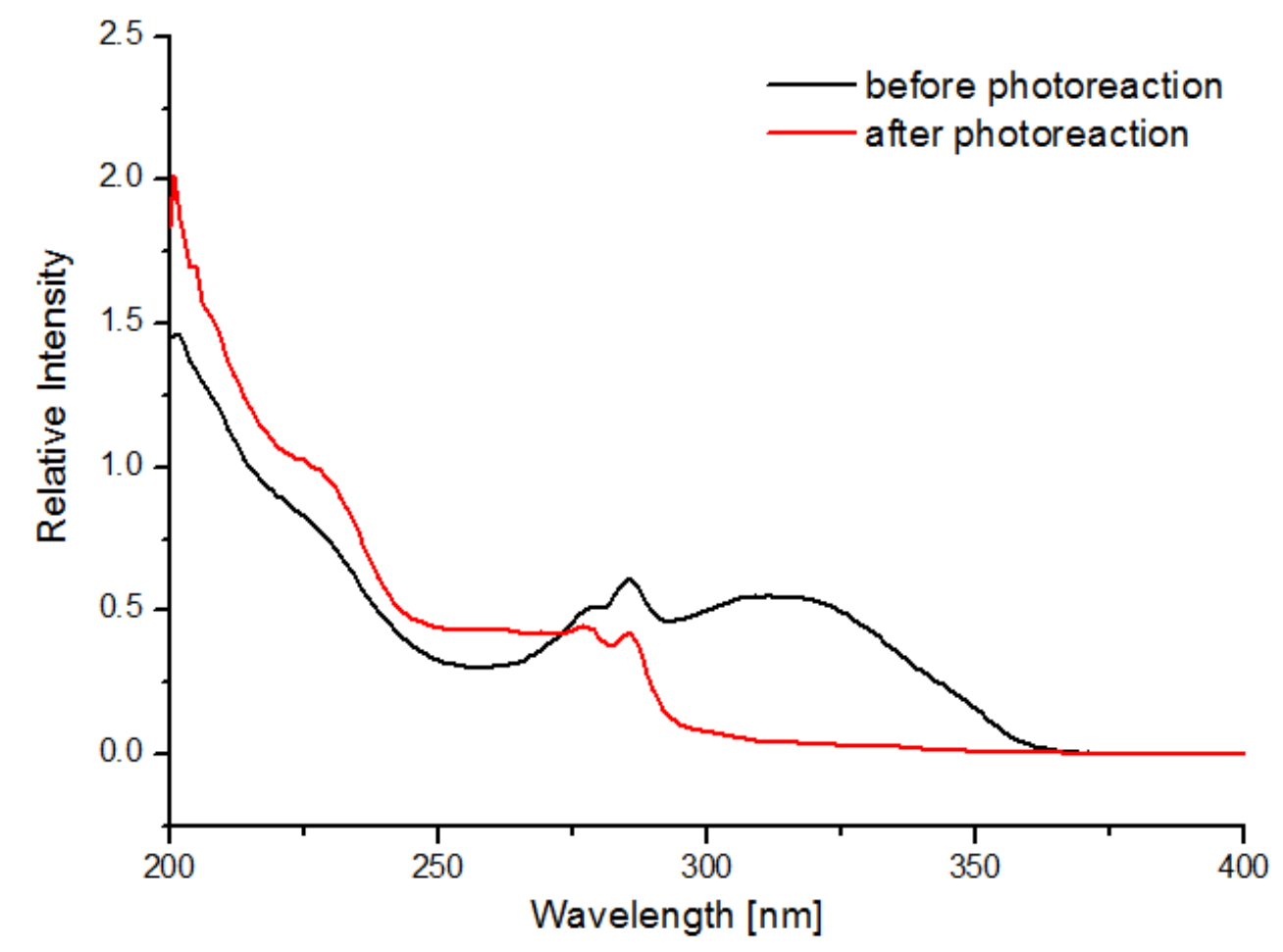

Figure S2. UV-Vis spectra of $\left[\mathrm{Ag}_{2}(2)_{2}\right]\left(\mathrm{PF}_{6}\right)_{2}(5 \mu \mathrm{M})$ in $\mathrm{CH}_{3} \mathrm{CN}$ before (dark line) and after (red line) photoreaction. 


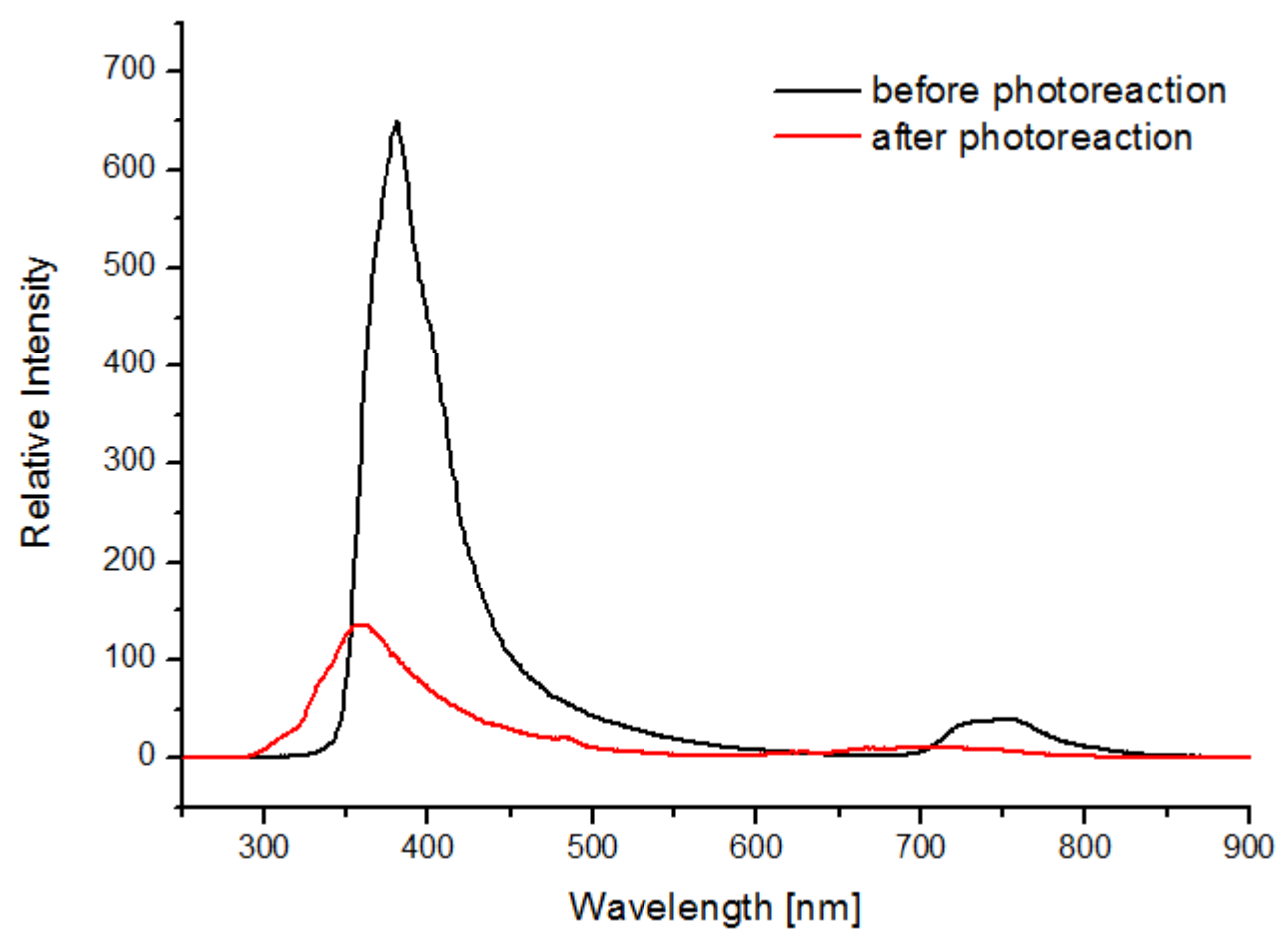

Figure S3. Fluorescence spectra of $\left[\mathrm{Ag}_{2}(\mathbf{1})_{2}\right]\left(\mathrm{PF}_{6}\right)_{2}(50 \mu \mathrm{M})$ in $\mathrm{CH}_{3} \mathrm{CN}$ before (dark line) and after (red line) photoreaction (excitation at $240 \mathrm{~nm}$ ).

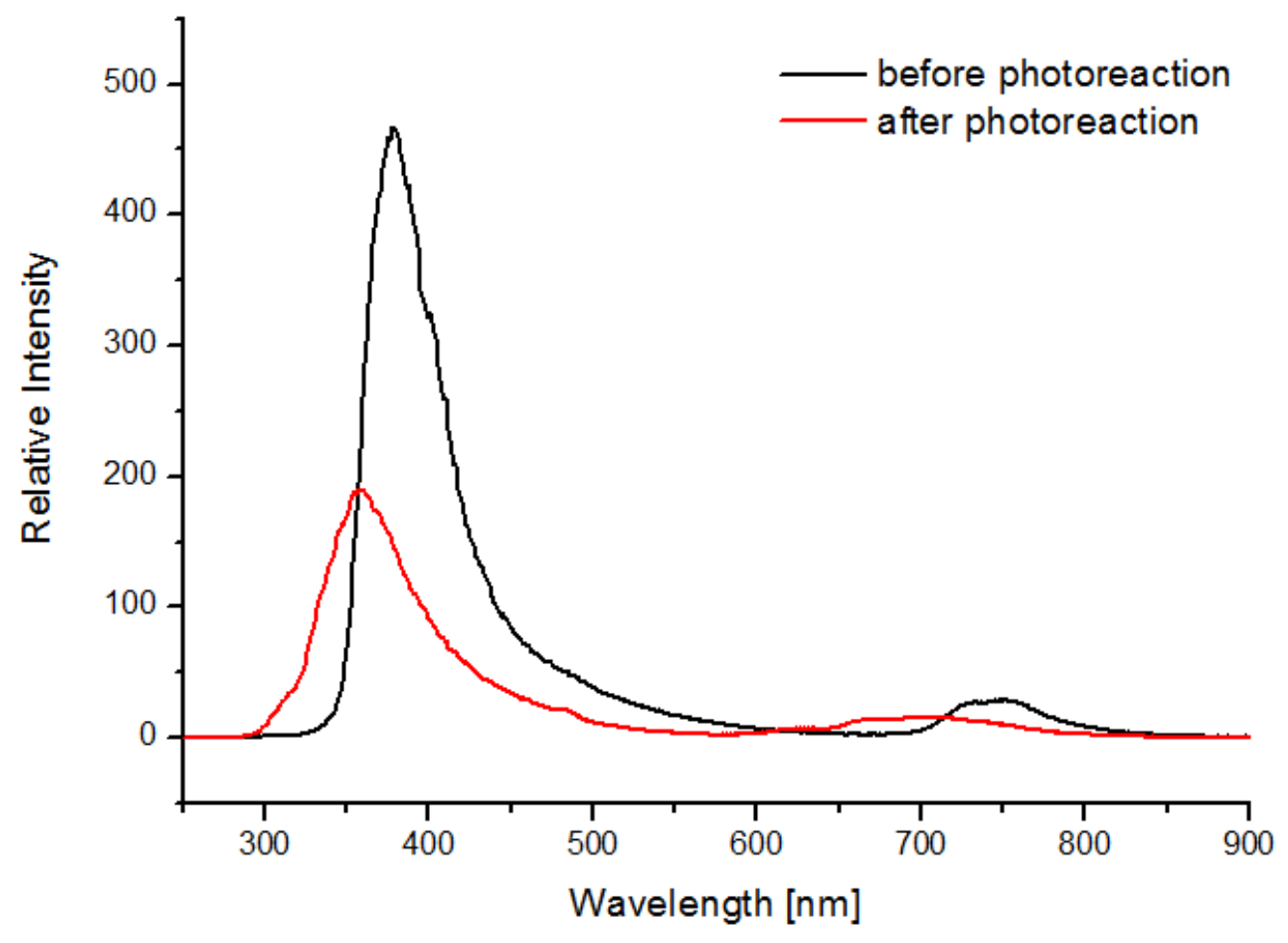

Figure S4. Fluorescence spectra of $\left[\mathrm{Ag}_{2}(2)_{2}\right]\left(\mathrm{PF}_{6}\right)_{2}(50 \mu \mathrm{M})$ in $\mathrm{CH}_{3} \mathrm{CN}$ before (dark line) and after (red line) photoreaction (excitation at $240 \mathrm{~nm}$ ). 


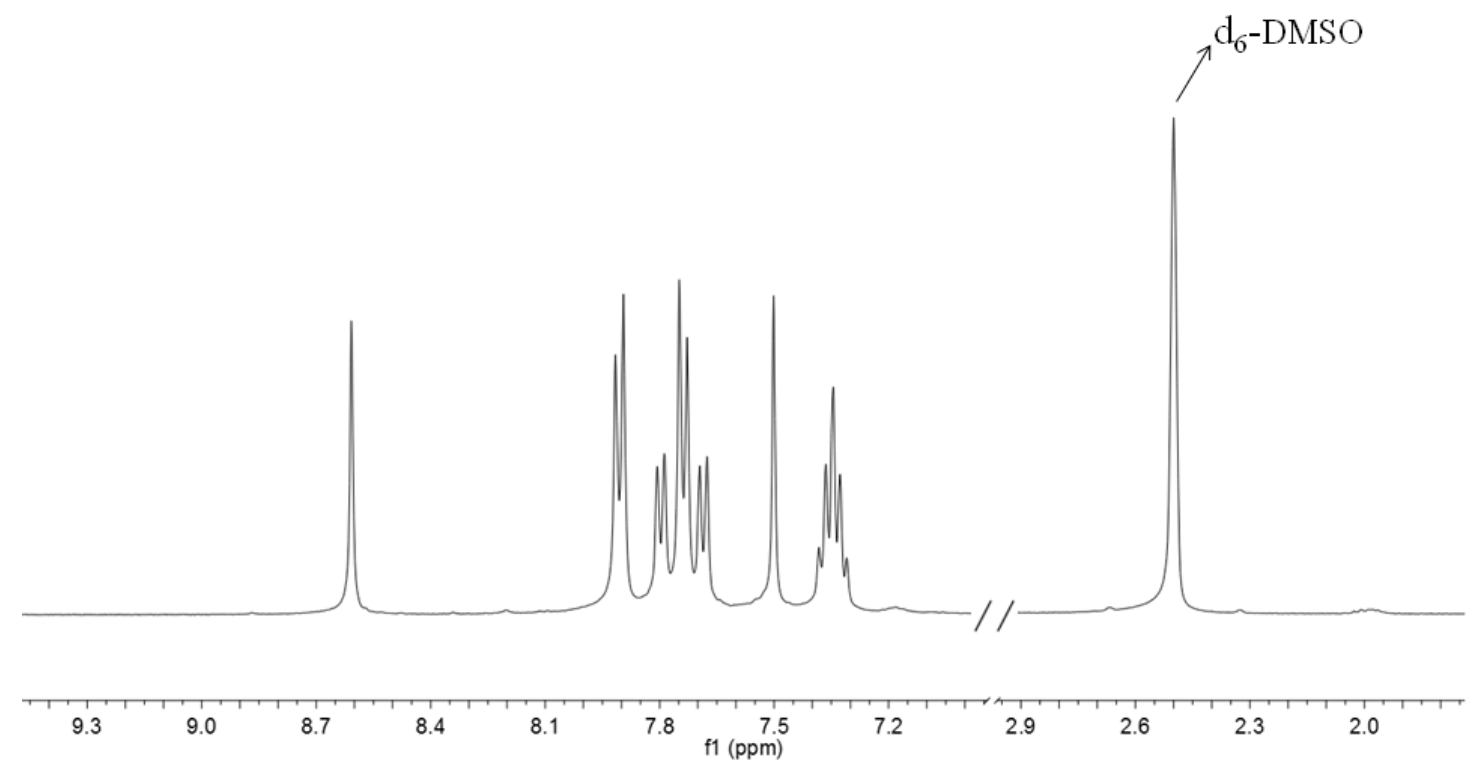

Figure S5. ${ }^{1} \mathrm{H}$ NMR (400 MHz, DMSO- $d_{6}$ ) of trans-4,4'-bis(1-benzoimidazolyl) stilbene

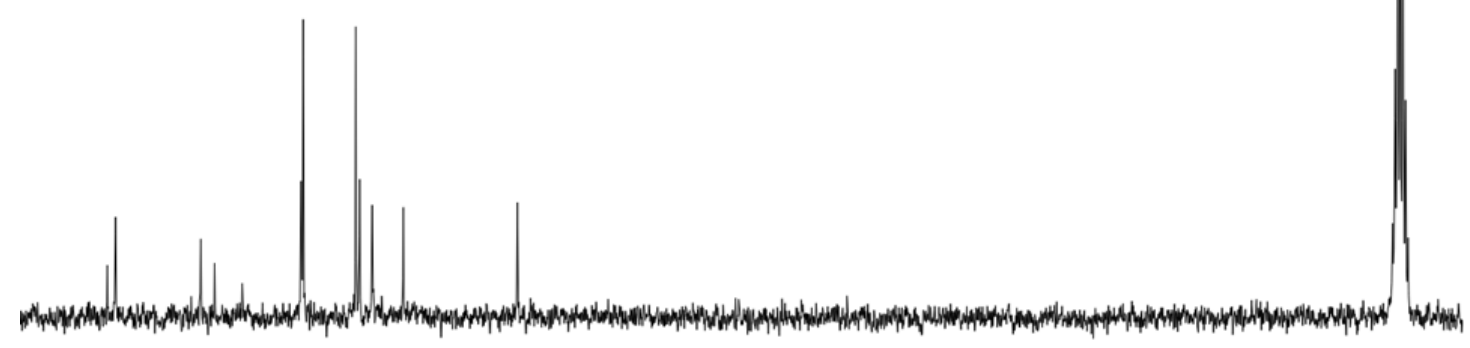

$\begin{array}{llllllllllllllllllllllllll}50 & 145 & 140 & 135 & 130 & 125 & 120 & 115 & 110 & 105 & 100 & \begin{array}{c}95 \\ \mathrm{f} 1(\mathrm{ppm})\end{array} & 85 & 80 & 75 & 70 & 65 & 60 & 55 & 50 & 45 & 40 & 35\end{array}$

Figure S6. ${ }^{13} \mathrm{C}$ NMR (100 MHz, DMSO- $\left.d_{6}\right)$ of trans-4,4'-bis(1-benzoimidazolyl) stilbene 


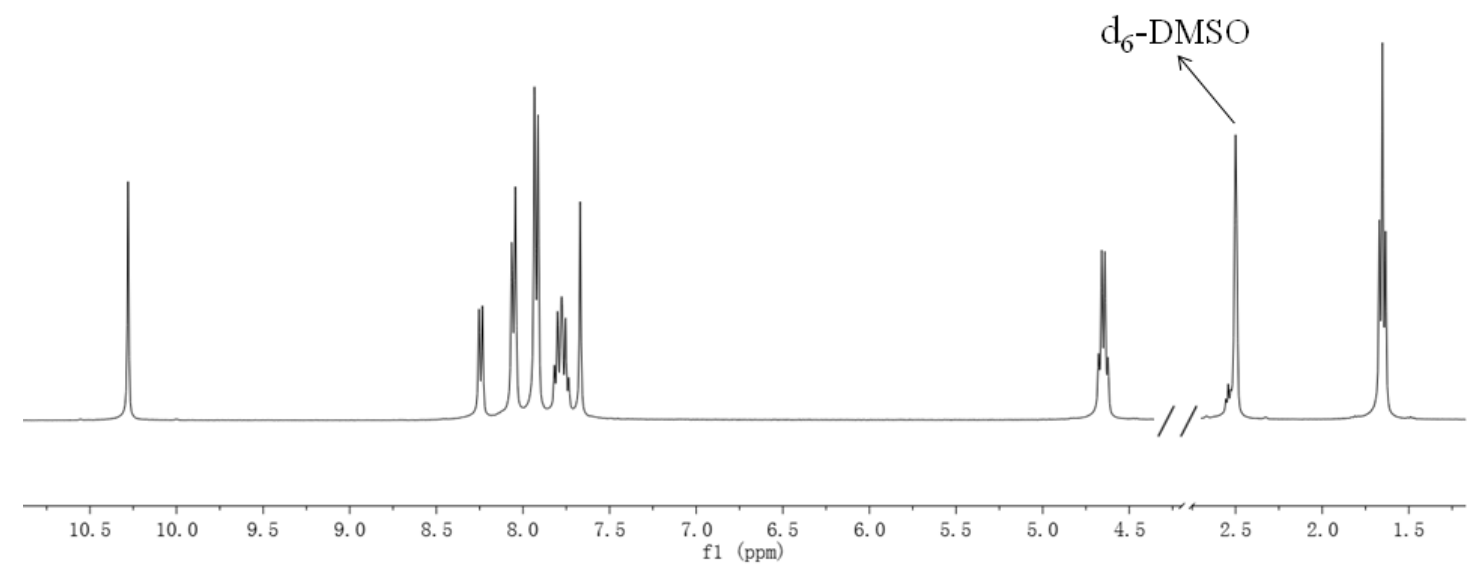

Figure S7. ${ }^{1} \mathrm{H}$ NMR $\left(400 \mathrm{MHz}, \mathrm{DMSO}-d_{6}\right)$ of $\mathrm{H}_{2}-\mathbf{1}(\mathrm{Br})_{2}$

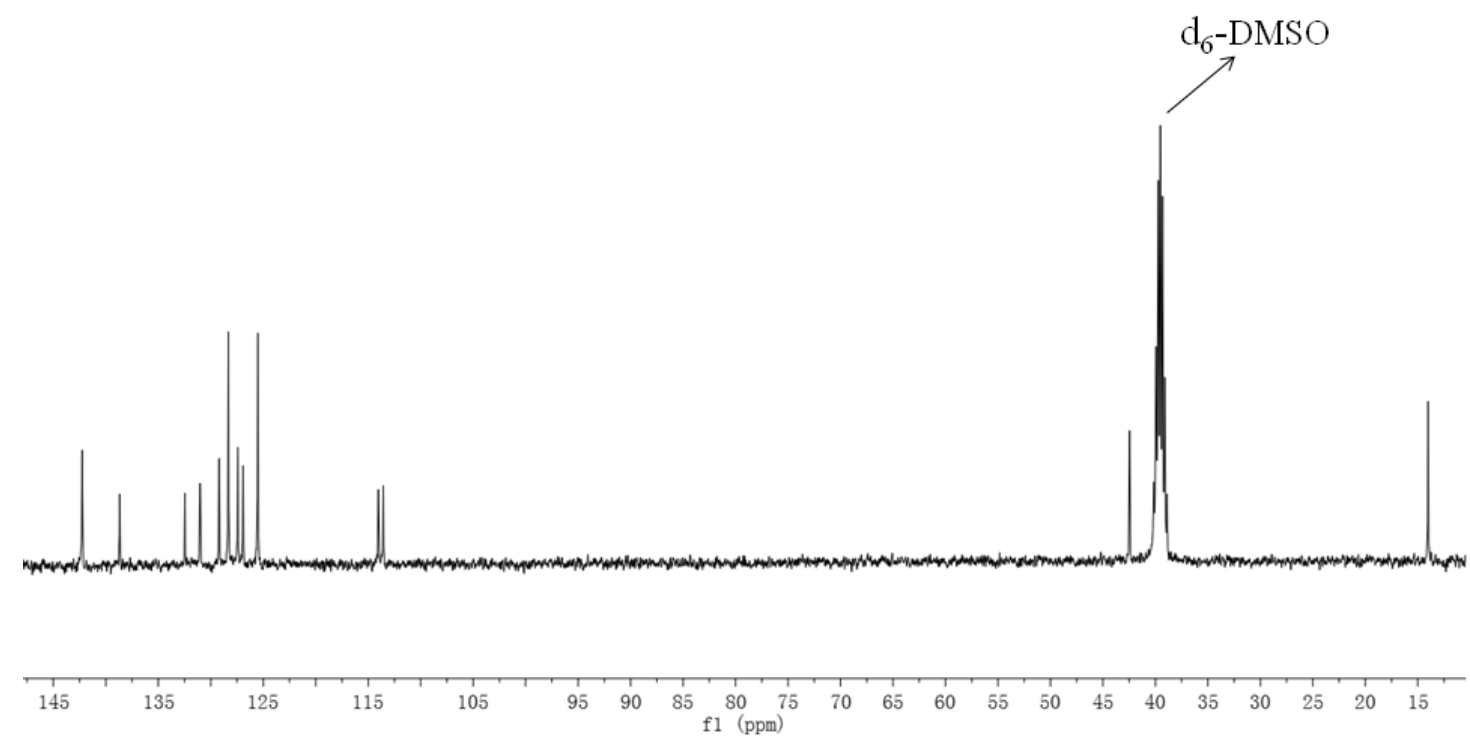

Figure S8. ${ }^{13} \mathrm{C}$ NMR $\left(100 \mathrm{MHz}, \mathrm{DMSO}-d_{6}\right)$ of $\mathrm{H}_{2}-\mathbf{1}(\mathrm{Br})_{2}$ 

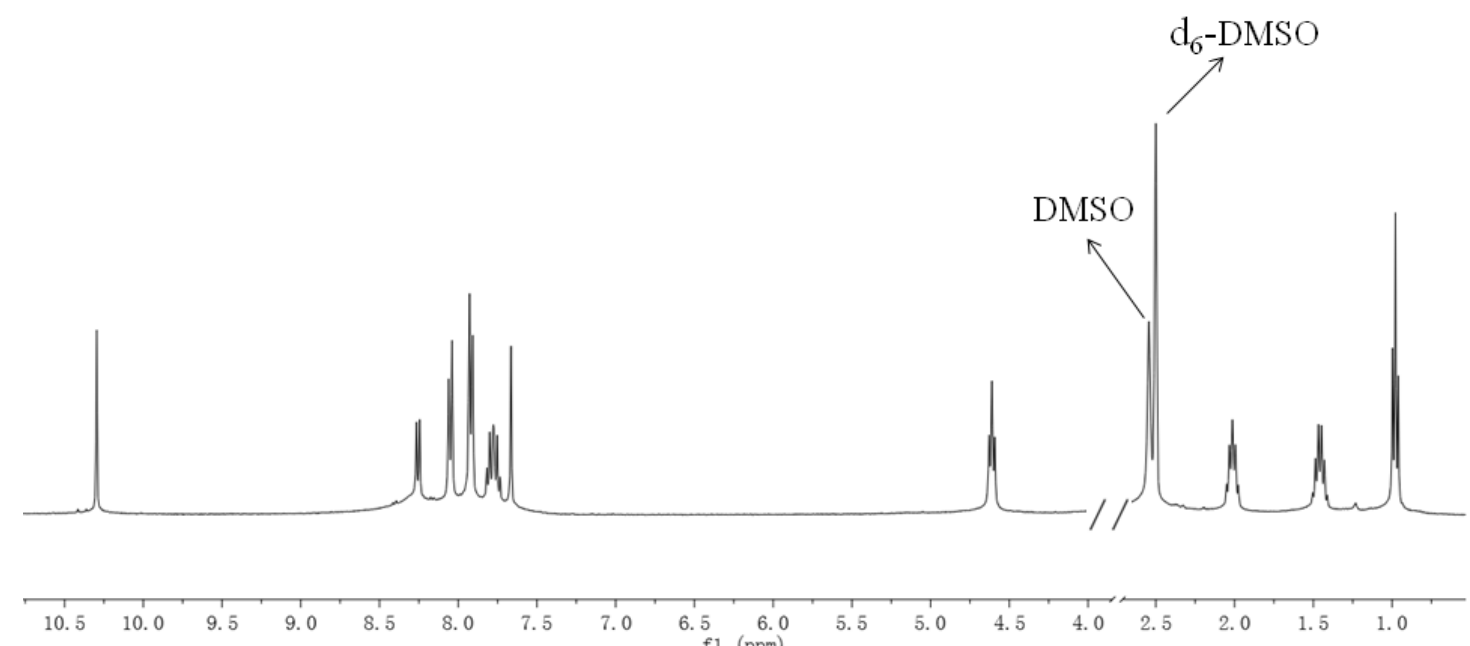

Figure S9. ${ }^{1} \mathrm{H} \mathrm{NMR}\left(400 \mathrm{MHz}, \mathrm{CD}_{3} \mathrm{CN}\right)$ of $\mathrm{H}_{2}-\mathbf{1}\left(\mathrm{PF}_{6}\right)_{2}$

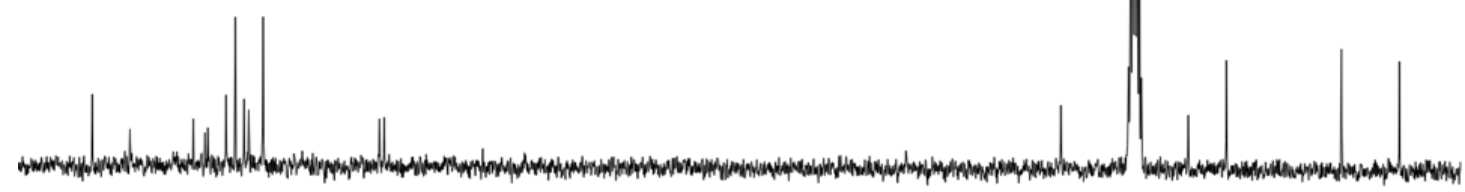

$\mathrm{d}_{6}$-DMSO

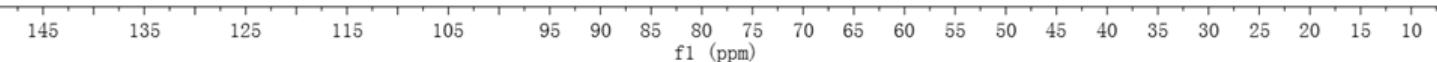

Figure S10. ${ }^{13} \mathrm{C}$ NMR $\left(100 \mathrm{MHz}, \mathrm{DMSO}-d_{6}\right)$ of $\mathrm{H}_{2}-\mathbf{1}\left(\mathrm{PF}_{6}\right)_{2}$ 


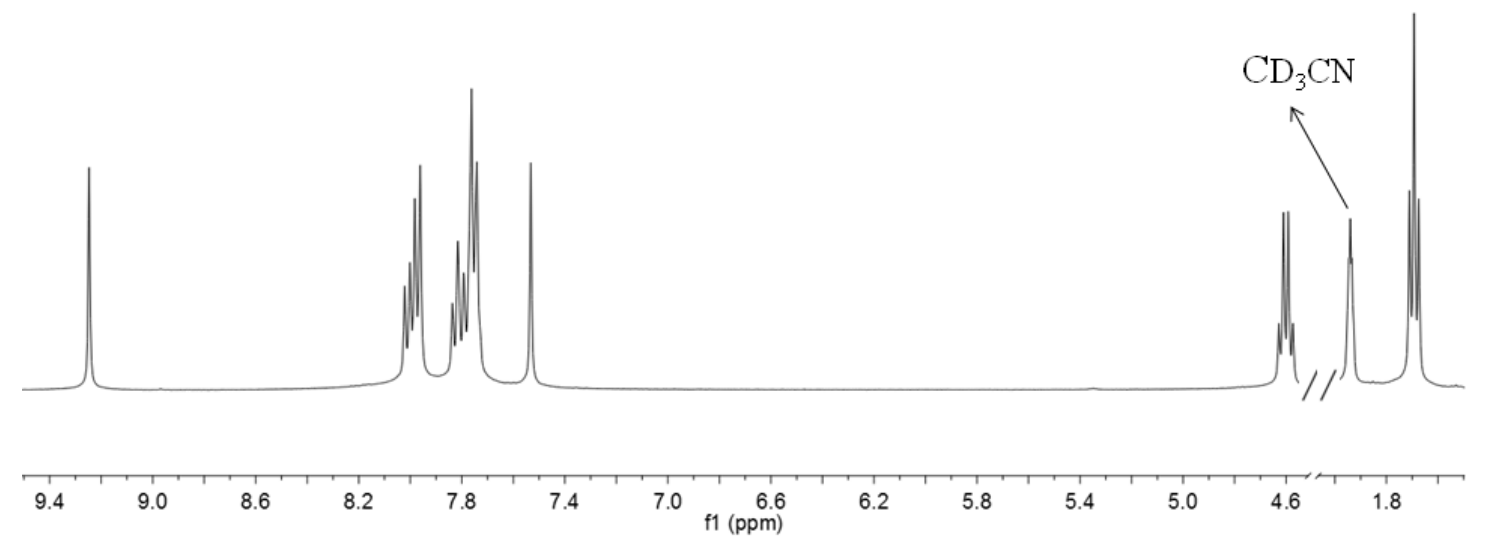

Figure S11. ${ }^{1} \mathrm{H}$ NMR (400 MHz, DMSO-d ${ }_{6}$ of $\mathrm{H}_{2}-2(\mathrm{Br})_{2}$

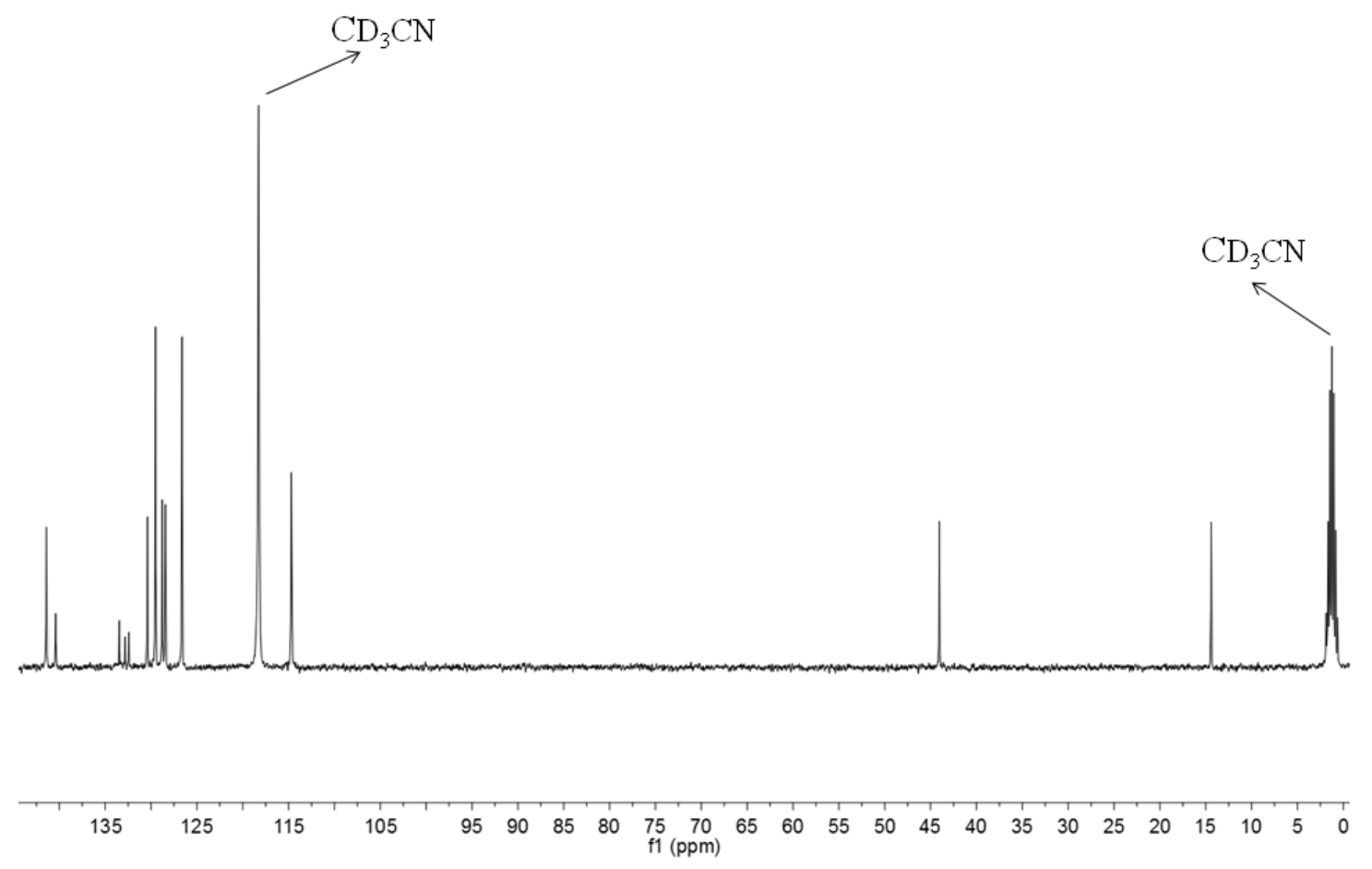

Figure S12. ${ }^{13} \mathrm{C}$ NMR (100 MHz, DMSO- $\left.d_{6}\right)$ of $\mathrm{H}_{2}-2(\mathrm{Br})_{2}$ 


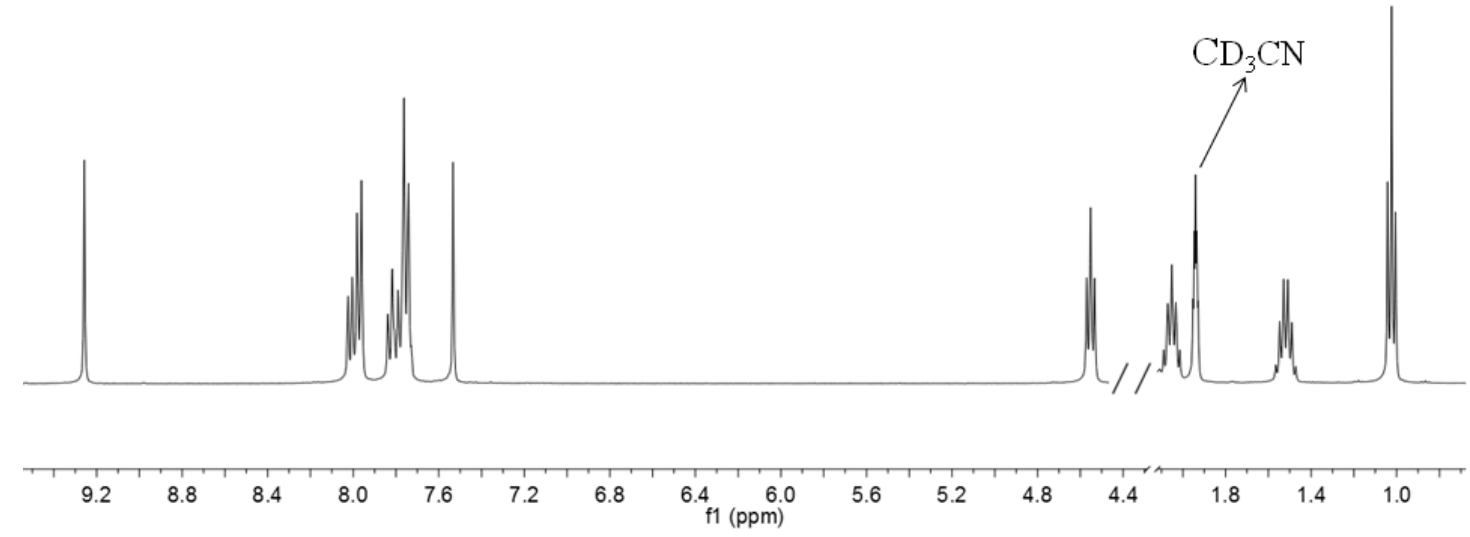

Figure S13. ${ }^{1} \mathrm{H}$ NMR (400 MHz, $\left.\mathrm{CD}_{3} \mathrm{CN}\right)$ of $\mathrm{H}_{2}-2\left(\mathrm{PF}_{6}\right)_{2}$

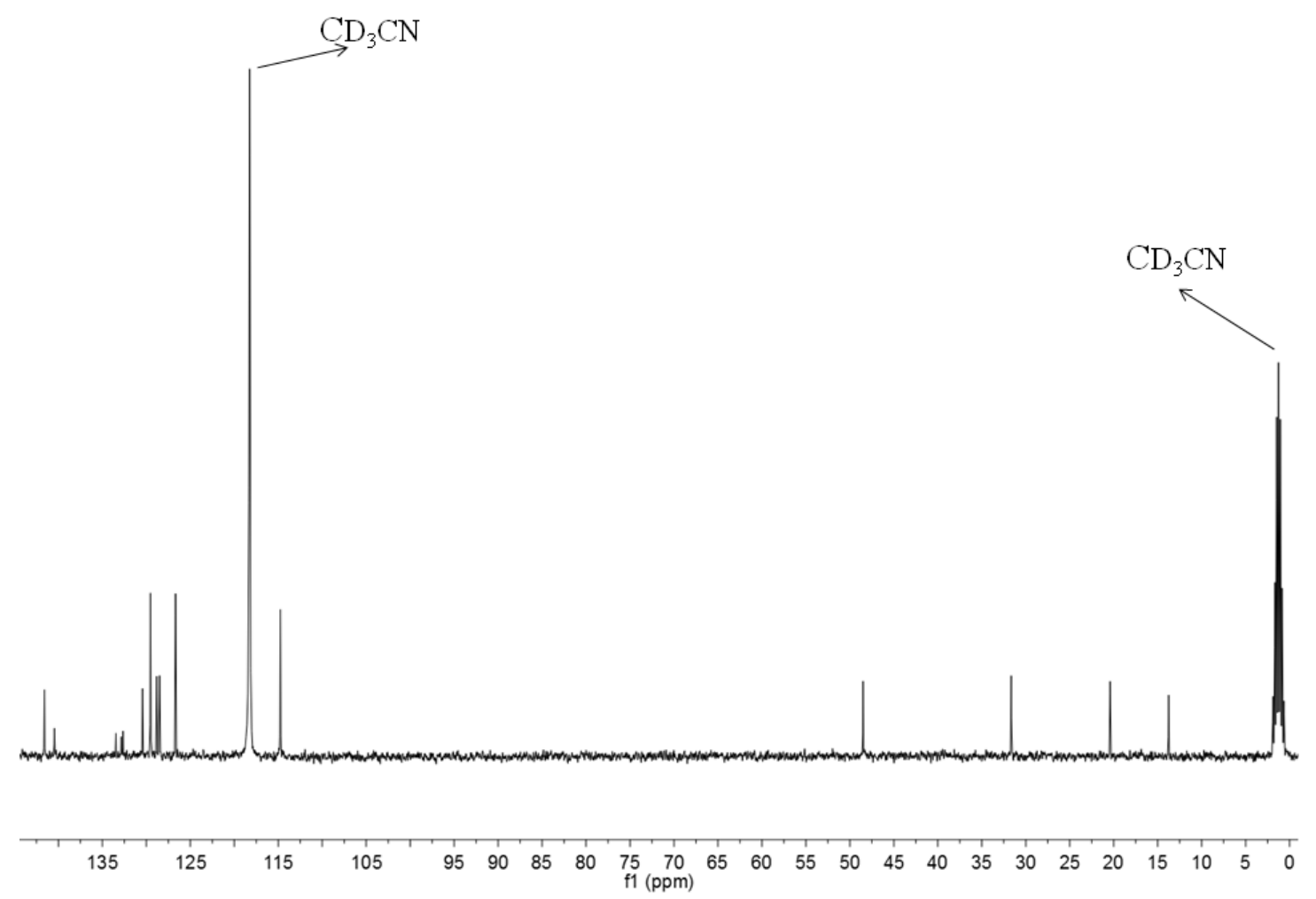

Figure S14. ${ }^{13} \mathrm{C}$ NMR (100 MHz, DMSO- $\left.d_{6}\right)$ of $\mathrm{H}_{2}-2\left(\mathrm{PF}_{6}\right)_{2}$ 


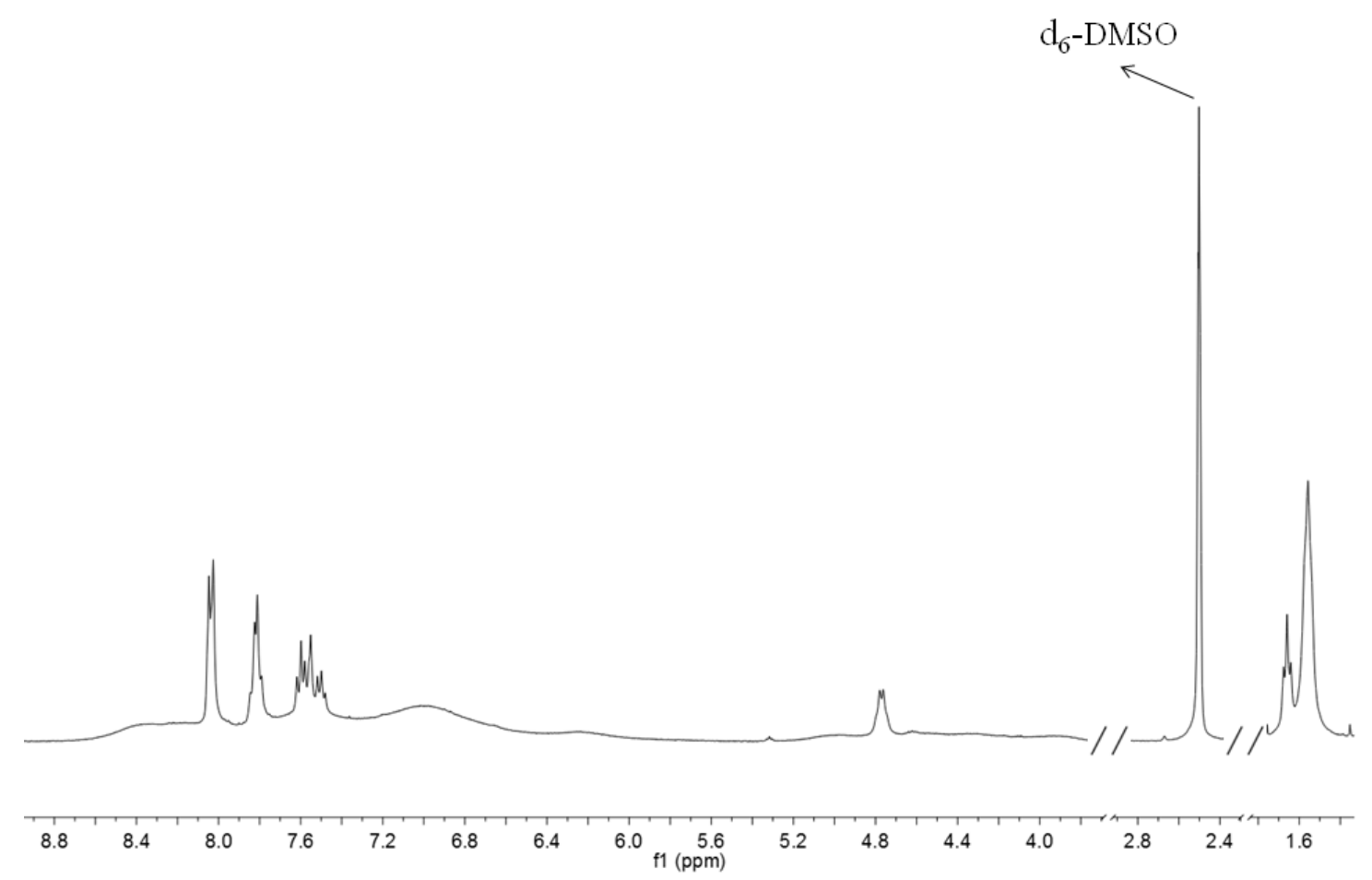

Figure S15. ${ }^{1} \mathrm{H}$ NMR (400 MHz, DMSO-d $d_{6}$ of $\left[\operatorname{Ag}_{2}(\mathbf{1})_{2}\right]\left(\mathrm{PF}_{6}\right)_{2}$

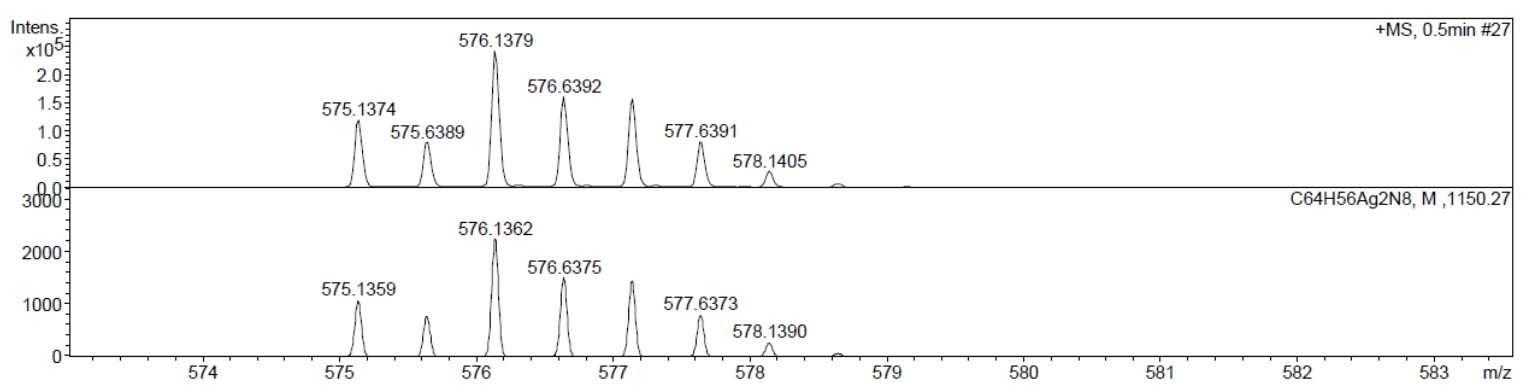

ESI-MS (positive ions) for $\left[\mathrm{Ag}_{2}(\mathbf{1})_{2}\right]^{2+}:$ Top (tested) and bottom (Calcd)

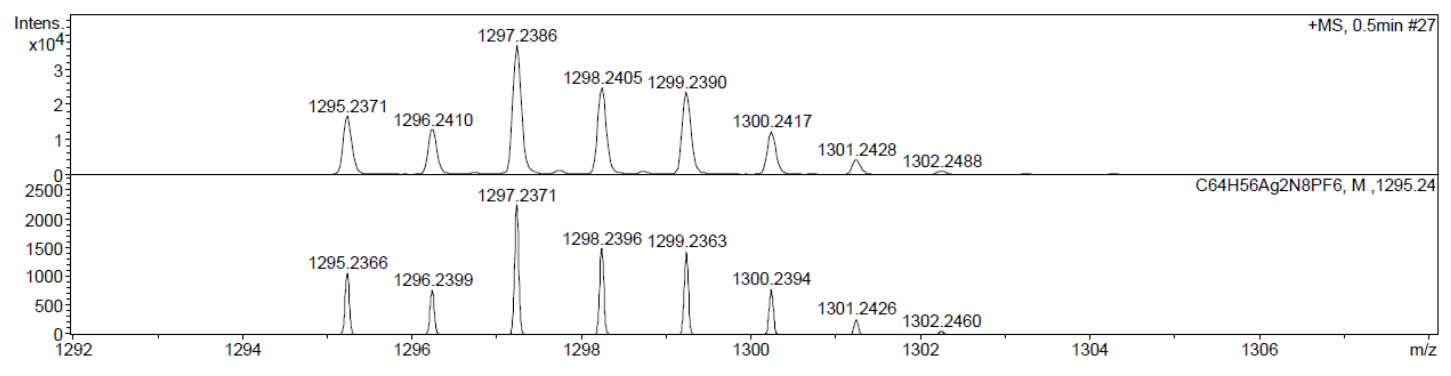

ESI-MS (positive ions) for $\left\{\left[\mathrm{Ag}_{2}(\mathbf{1})_{2}\right]\left(\mathrm{PF}_{6}\right)\right\}^{+}:$Top (tested) and bottom (Calcd)

Figure S16. ESI-MS spectra of $\left[\mathrm{Ag}_{2}(\mathbf{1})_{2}\right]\left(\mathrm{PF}_{6}\right)_{2}$ 


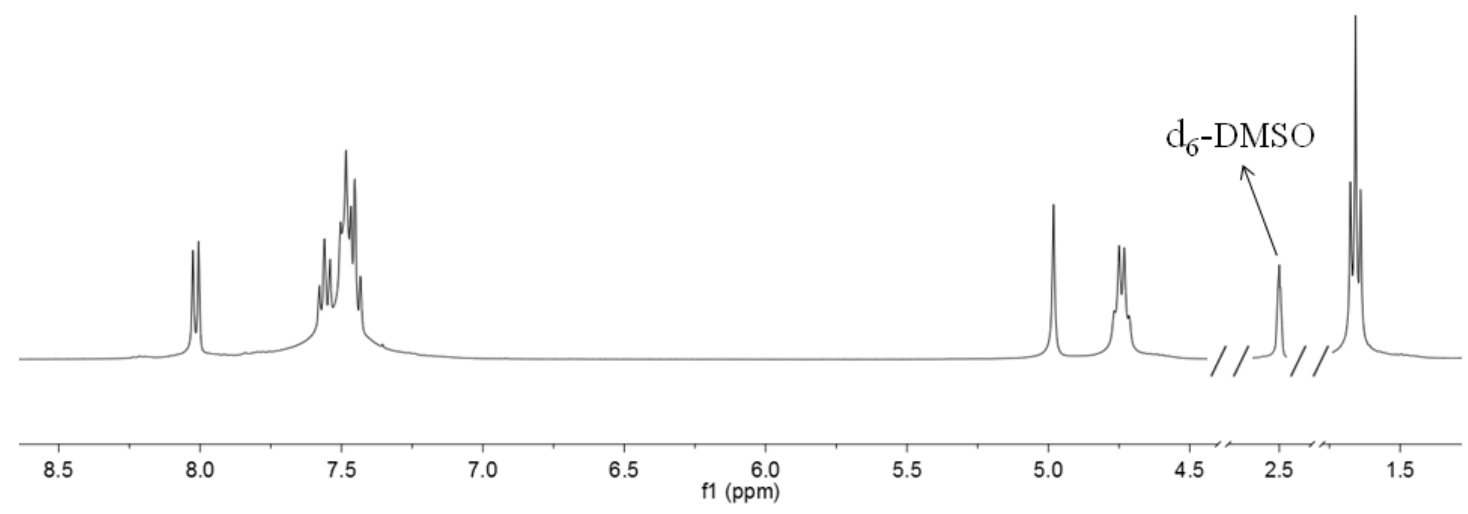

Figure S17. ${ }^{1} \mathrm{H} \mathrm{NMR}\left(400 \mathrm{MHz}, \mathrm{CD}_{3} \mathrm{CN}\right)$ of $\left[\mathrm{Ag}_{2}(3)_{2}\right]\left(\mathrm{PF}_{6}\right)_{2}$

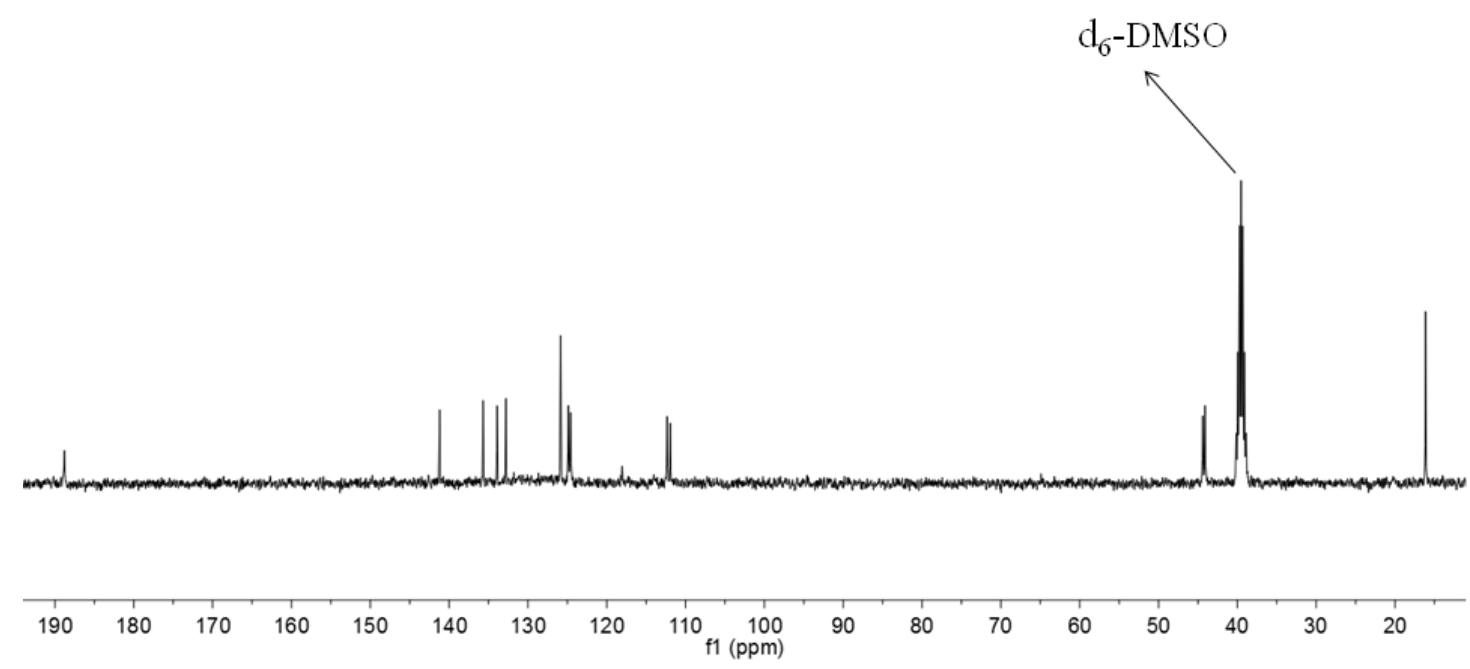

Figure S18. ${ }^{13} \mathrm{C}$ NMR (100 MHz, DMSO-d ${ }_{6}$ of $\left[\mathrm{Ag}_{2}(3)_{2}\right]\left(\mathrm{PF}_{6}\right)_{2}$ 


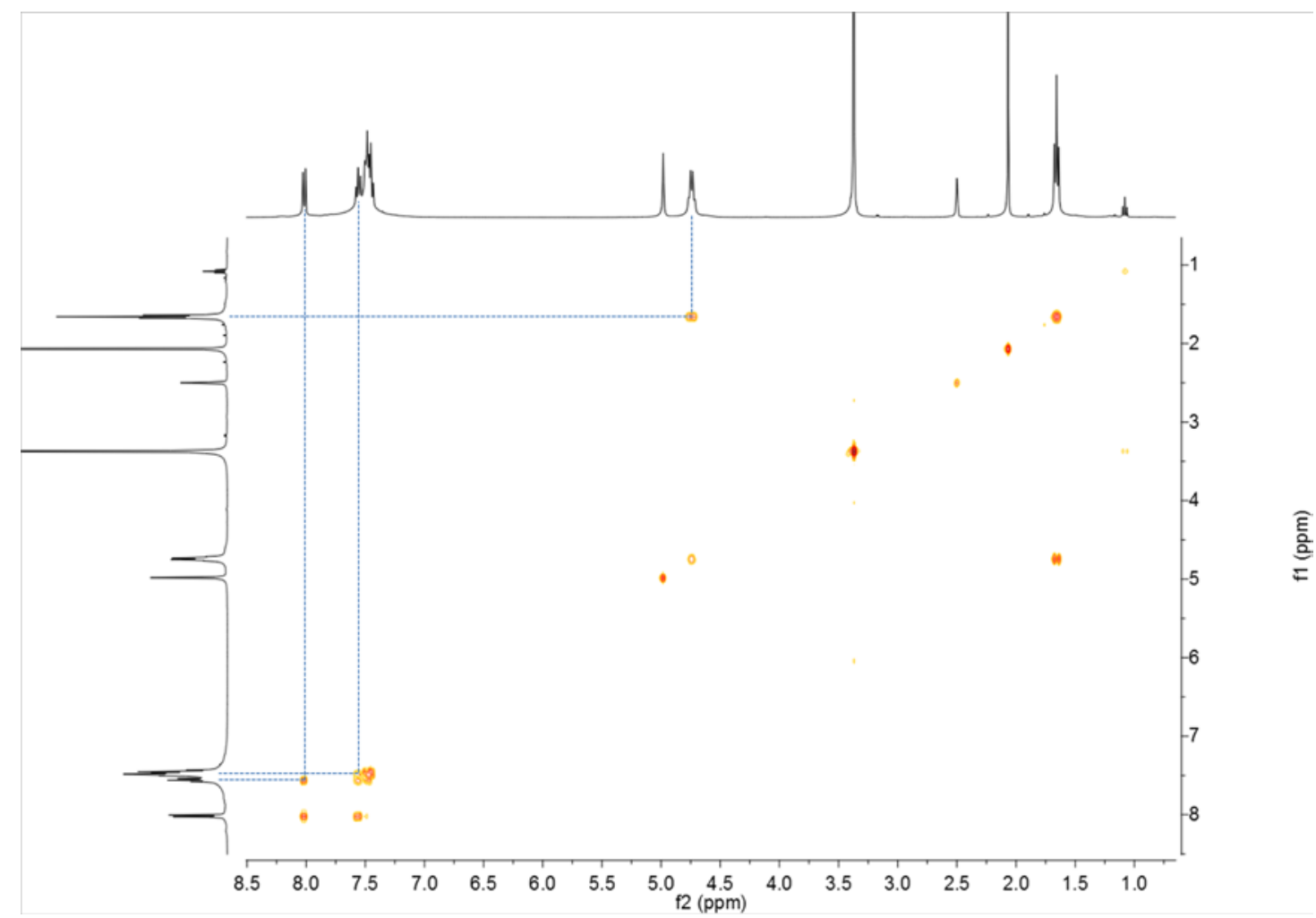

Figure S19. HH-COSY (DMSO- $\left.d_{6}\right)$ of $\left[\mathrm{Ag}_{2}(3)\right]\left(\mathrm{PF}_{6}\right)_{2}$

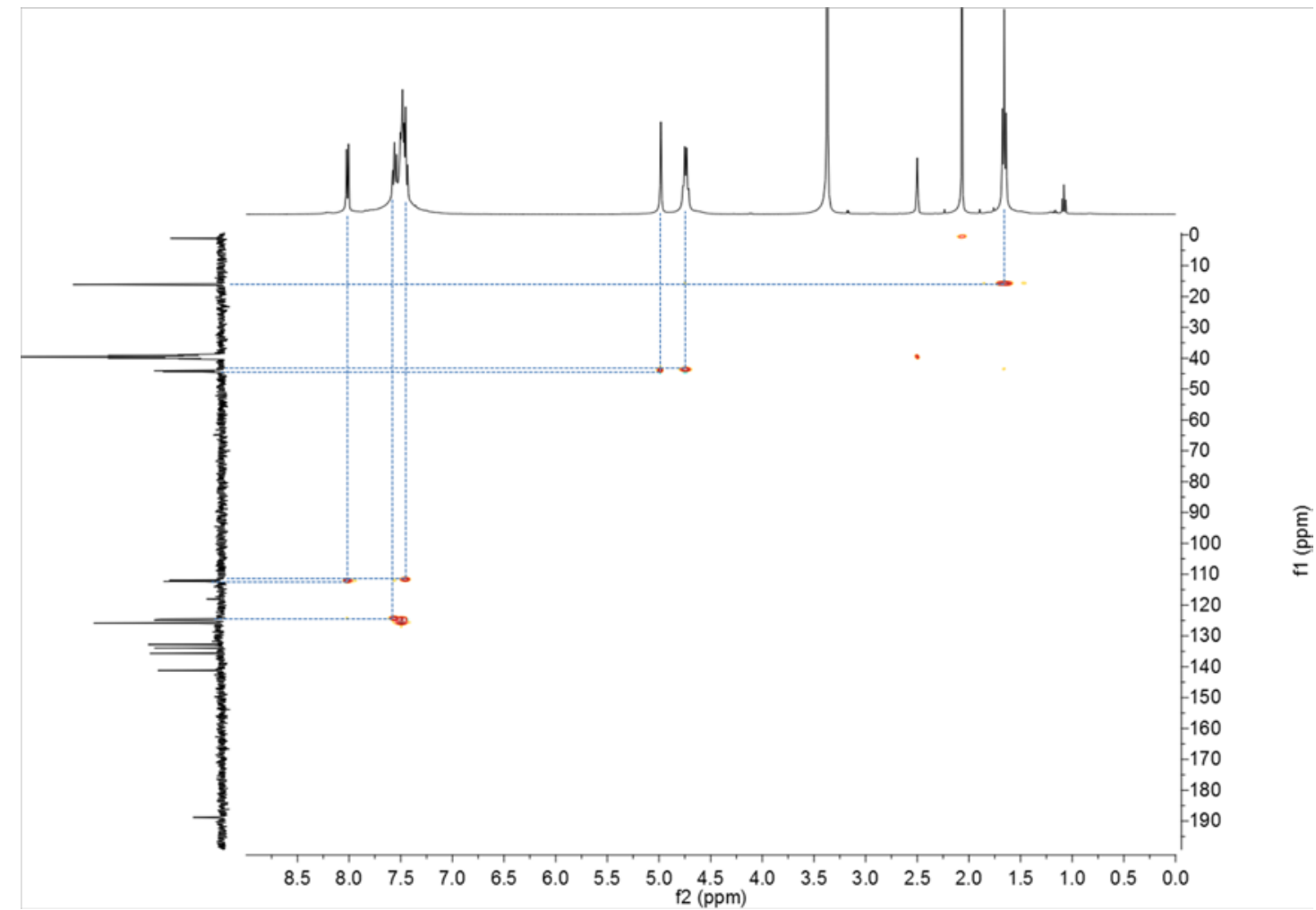

Figure S20. HC-HSQC (DMSO- $\left.d_{6}\right)$ of $\left[\mathrm{Ag}_{2}(3)\right]\left(\mathrm{PF}_{6}\right)_{2}$ 


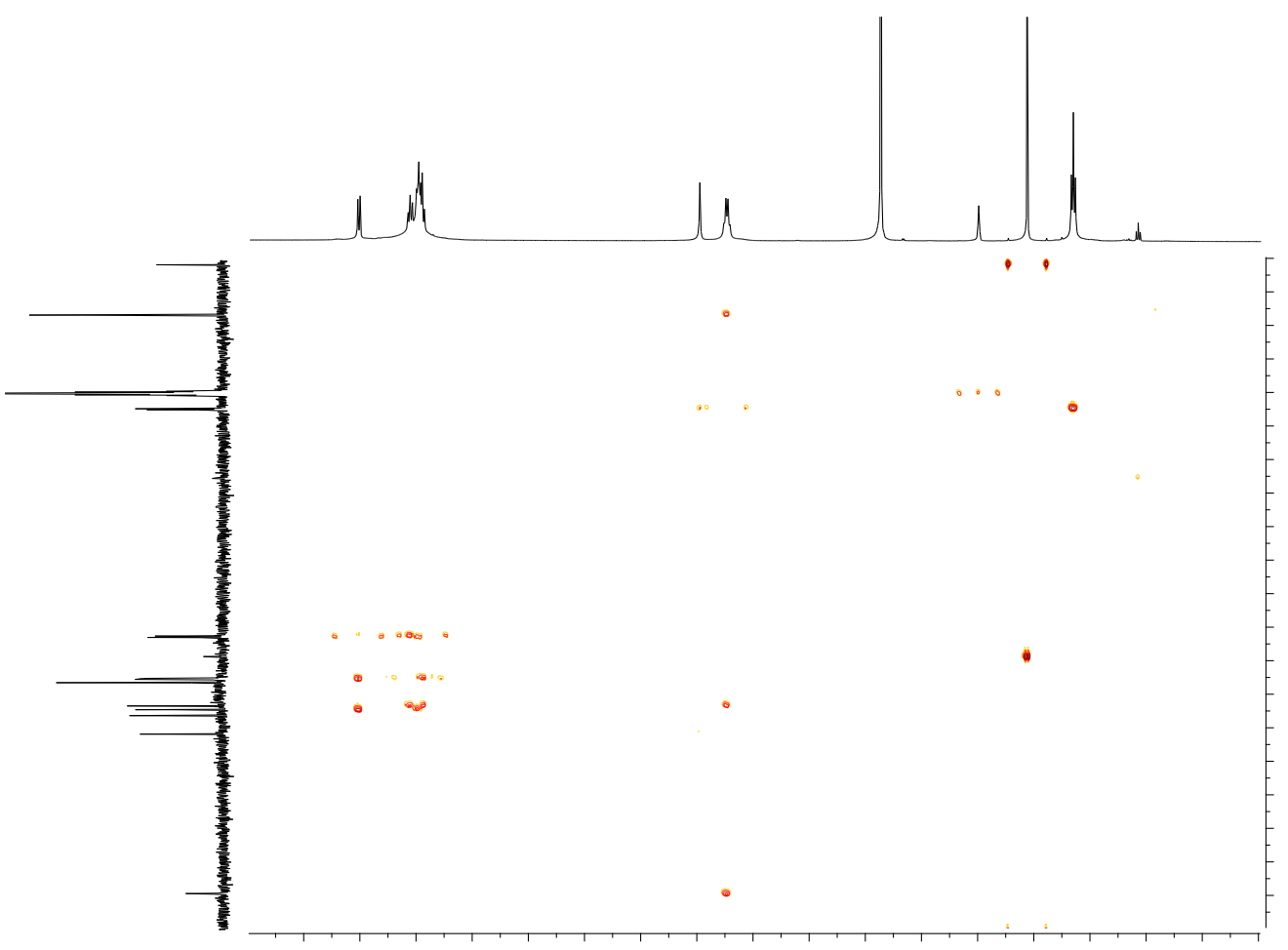

Figure S21. HC-HMQC (DMSO-d $\left.{ }_{6}\right)$ of $\left[\mathrm{Ag}_{2}(3)\right]\left(\mathrm{PF}_{6}\right)_{2}$

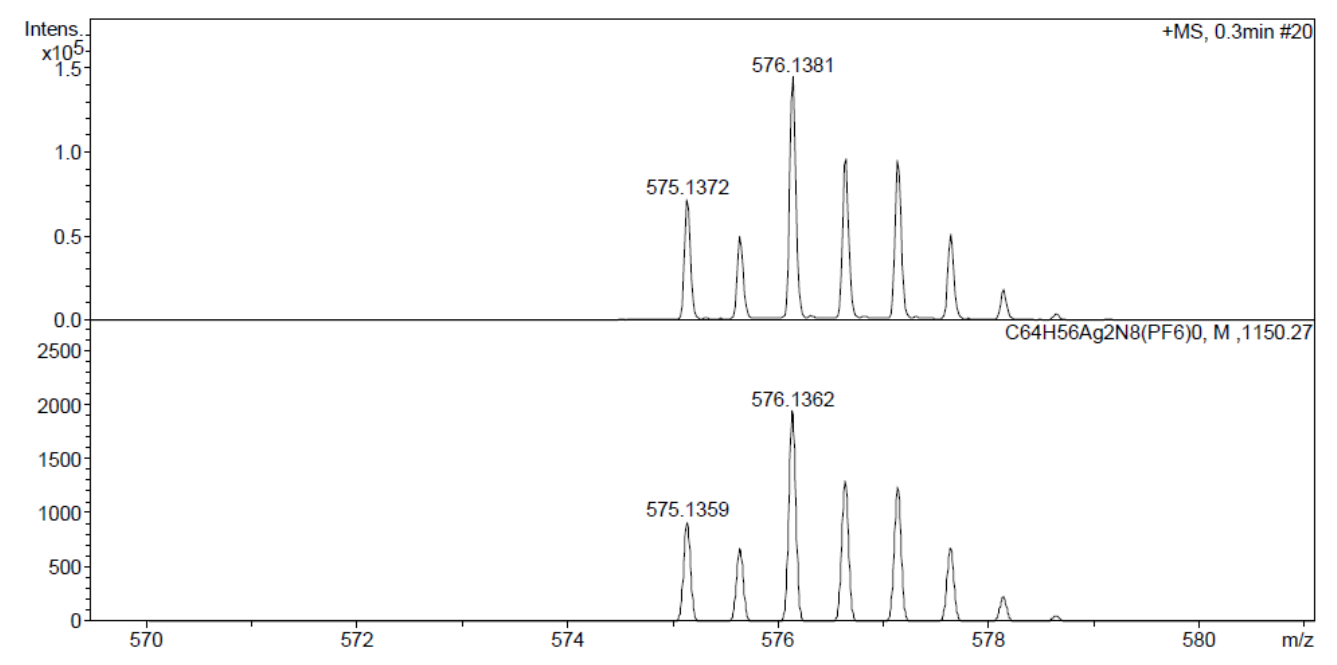

ESI-MS (positive ions) for $\left[\mathrm{Ag}_{2}(3)\right]^{2+}:$ Top (tested) and bottom (Calcd) 


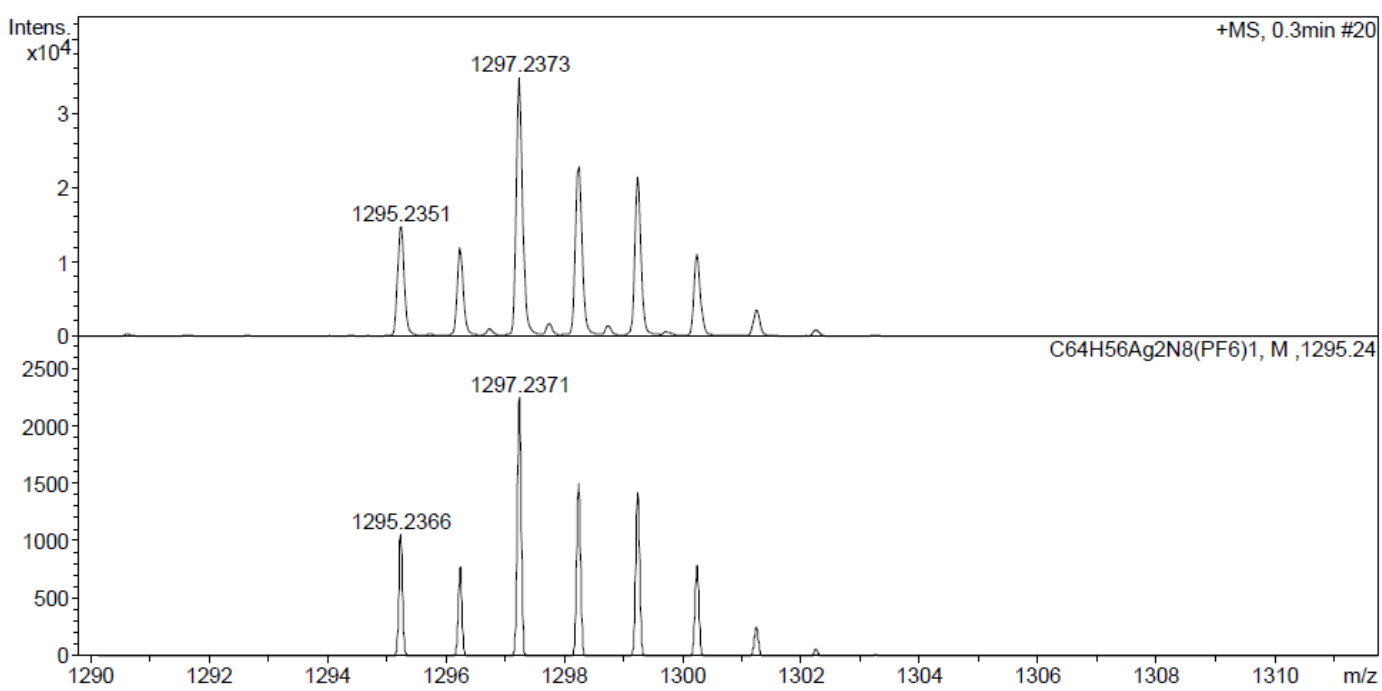

ESI-MS (positive ions) for $\left\{\left[\mathrm{Ag}_{2}(3)\right]\left(\mathrm{PF}_{6}\right)\right\}^{+}$: Top (tested) and bottom (Calcd)

Figure S22. ESI-MS spectra of $\left[\mathrm{Ag}_{2}(3)\right]\left(\mathrm{PF}_{6}\right)_{2}$

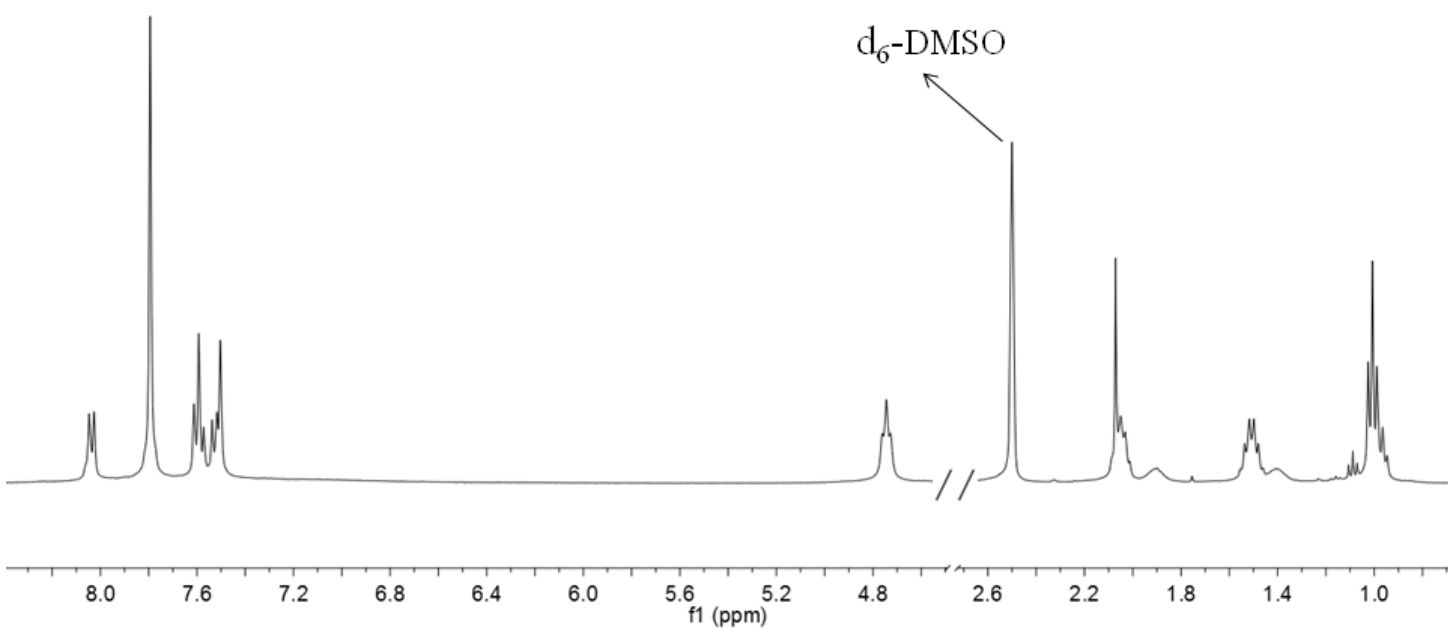

Figure S23. ${ }^{1} \mathrm{H}$ NMR $\left(400 \mathrm{MHz}\right.$, DMSO- $\left.d_{6}\right)$ of $\left[\mathrm{Ag}_{2}(2)_{2}\right]\left(\mathrm{PF}_{6}\right)_{2}$ 


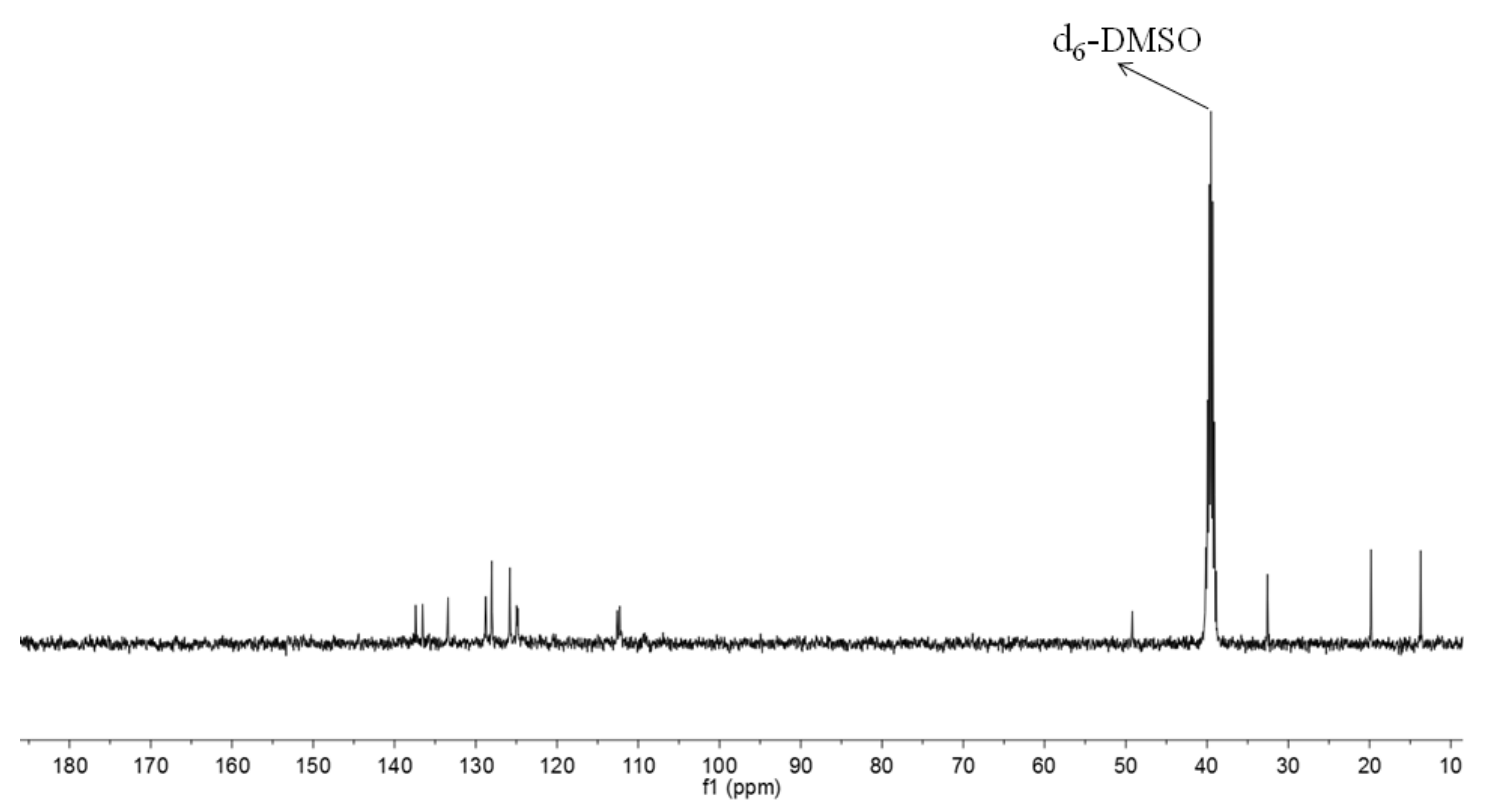

Figure S24. ${ }^{13} \mathrm{C}$ NMR (100 MHz, DMSO-d $\left.d_{6}\right)$ of $\left[\mathrm{Ag}_{2}(2)_{2}\right]\left(\mathrm{PF}_{6}\right)_{2}$

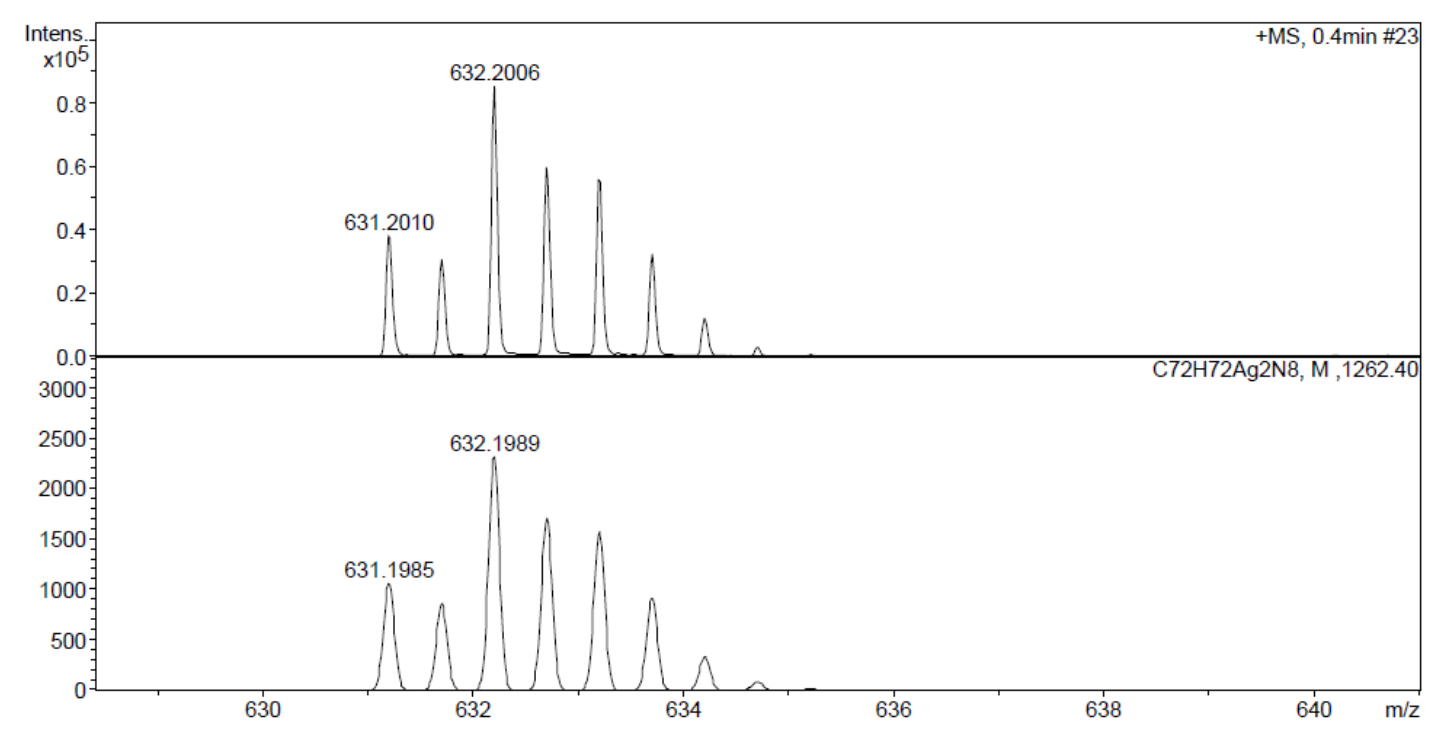

ESI-MS (positive ions) for $\left[\mathrm{Ag}_{2}(2)_{2}\right]^{2+}:$ Top (tested) and bottom (Calcd)

Figure S25. ESI-MS spectrum of $\left[\mathrm{Ag}_{2}(2)_{2}\right]\left(\mathrm{PF}_{6}\right)_{2}$ 


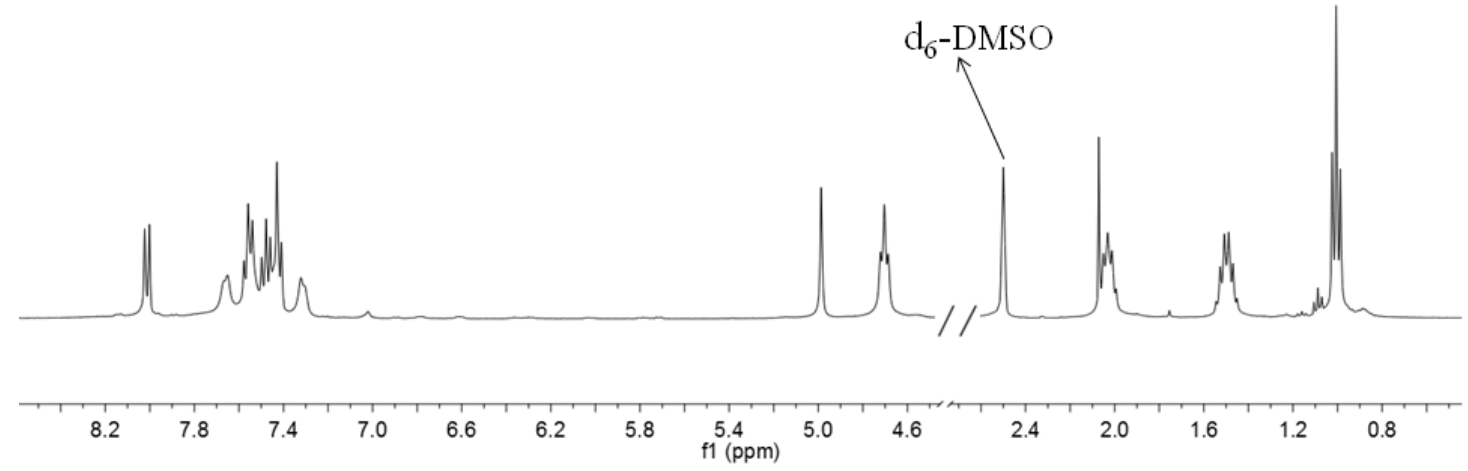

Figure S26. ${ }^{1} \mathrm{H}$ NMR (400 MHz, DMSO- $\left.d_{6}\right)$ of $\left[\mathrm{Ag}_{2}(4)\right]\left(\mathrm{PF}_{6}\right)_{2}$

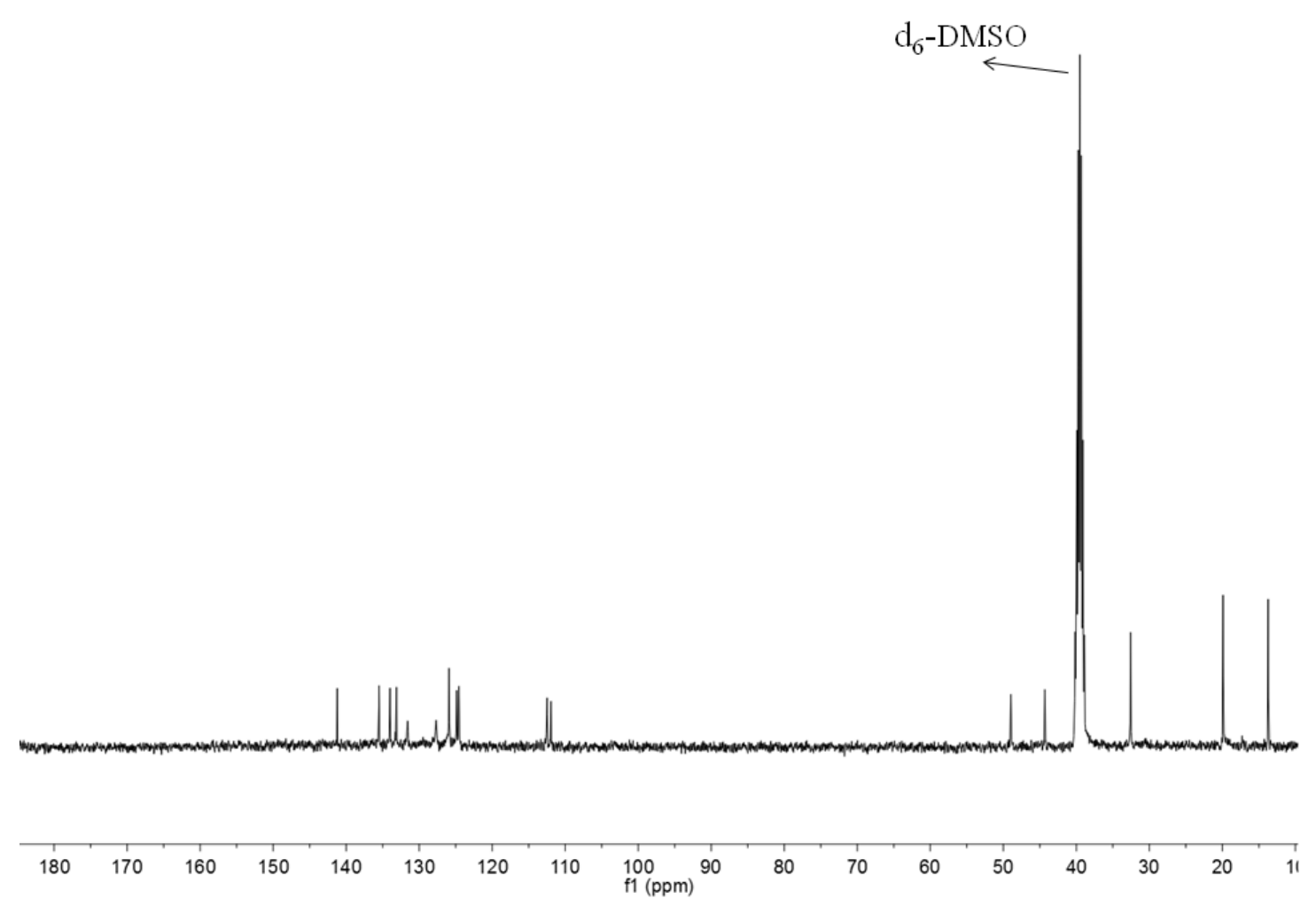

Figure S27. ${ }^{13} \mathrm{C}$ NMR (100 MHz, DMSO- $\left.d_{6}\right)$ of $\left[\mathrm{Ag}_{2}(4)\right]\left(\mathrm{PF}_{6}\right)_{2}$ 


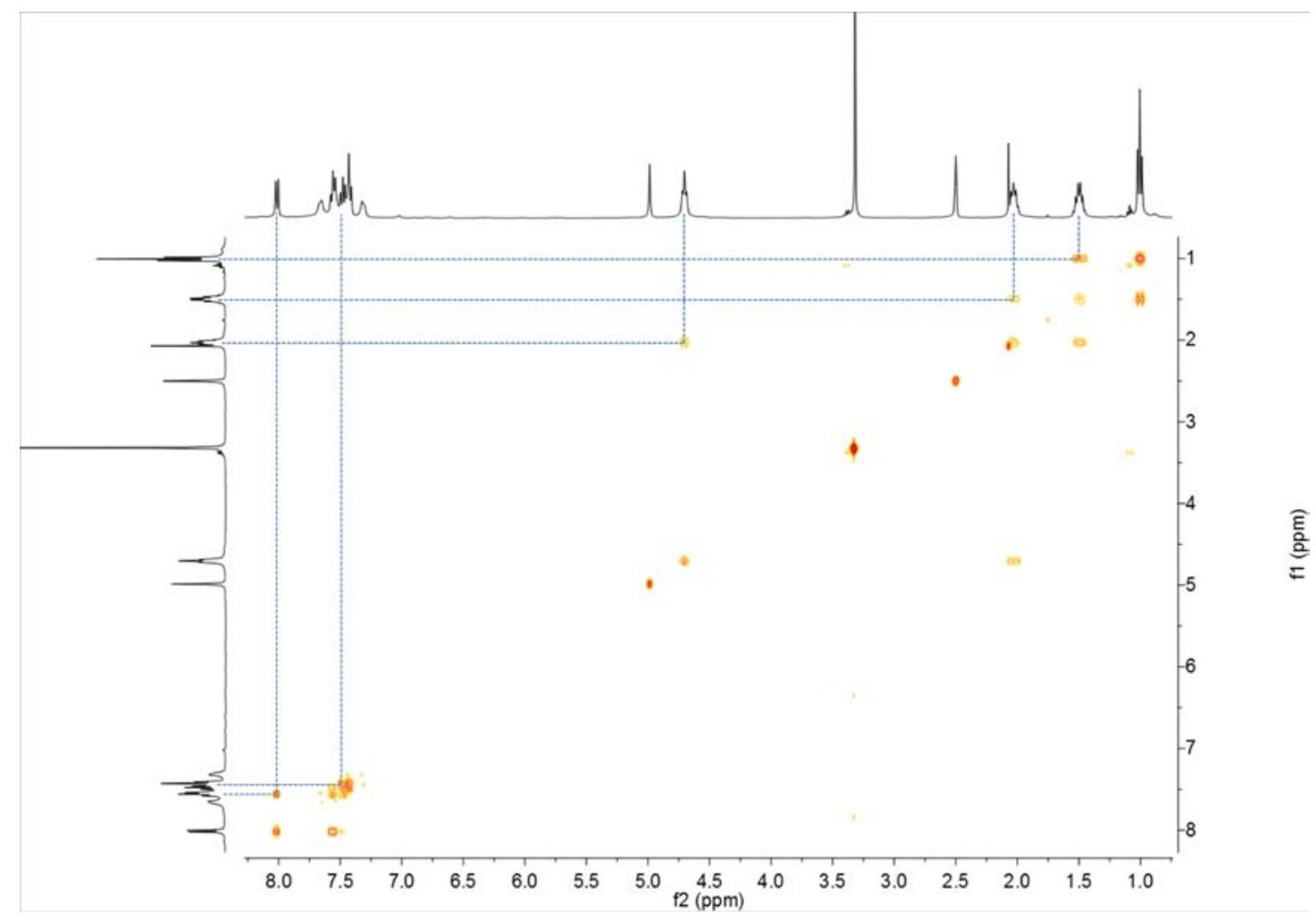

Figure S28. HH-COSY (DMSO- $\left.d_{6}\right)$ of $\left[\mathrm{Ag}_{2}(4)\right]\left(\mathrm{PF}_{6}\right)_{2}$

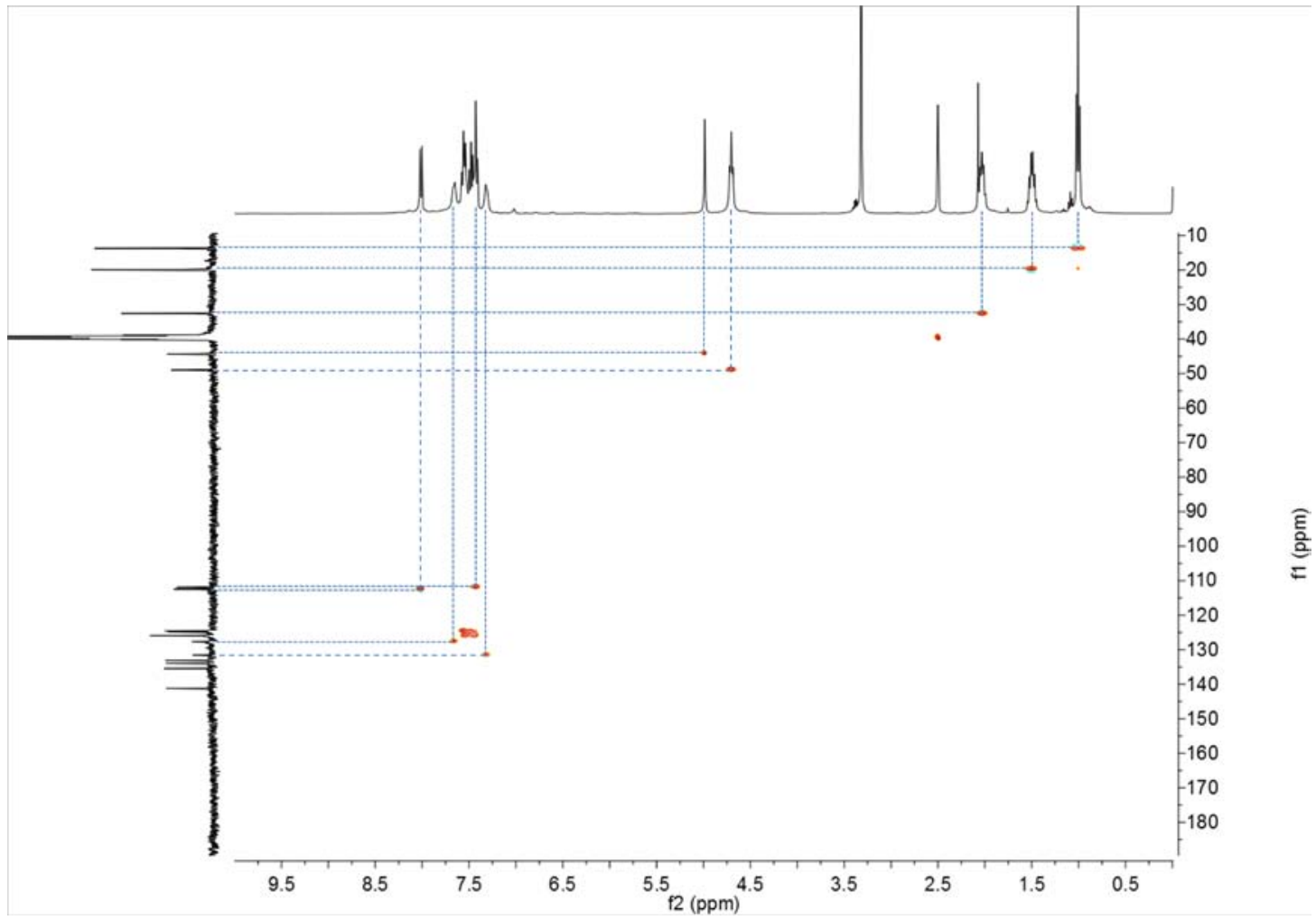

Figure S29. HC-HSQC $\left(\mathrm{DMSO}-d_{6}\right)$ of $\left[\mathrm{Ag}_{2}(4)\right]\left(\mathrm{PF}_{6}\right)_{2}$ 


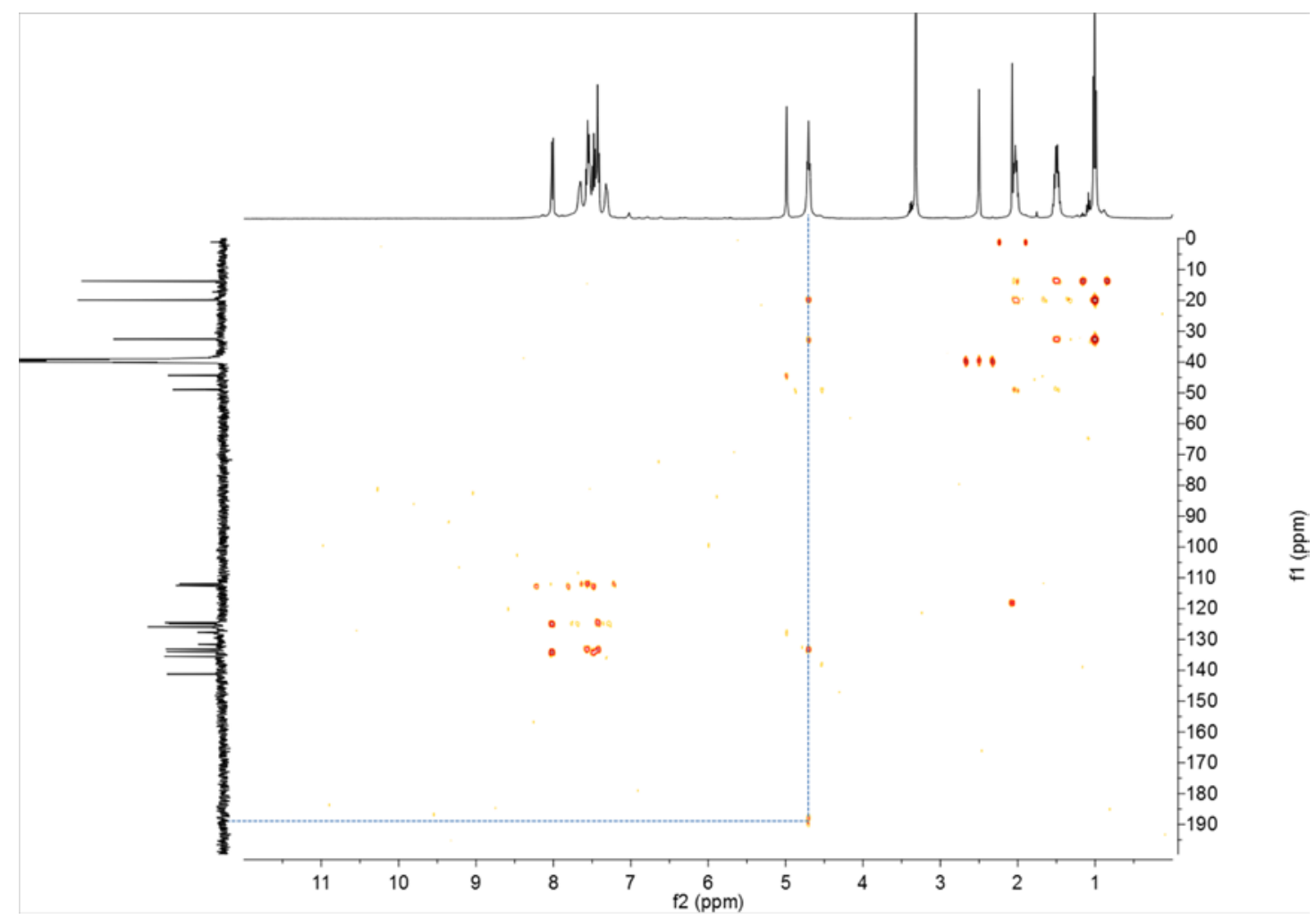

Figure S30. HC-HMQC (DMSO-d $\left.{ }_{6}\right)$ of $\left[\mathrm{Ag}_{2}(4)\right]\left(\mathrm{PF}_{6}\right)_{2}$

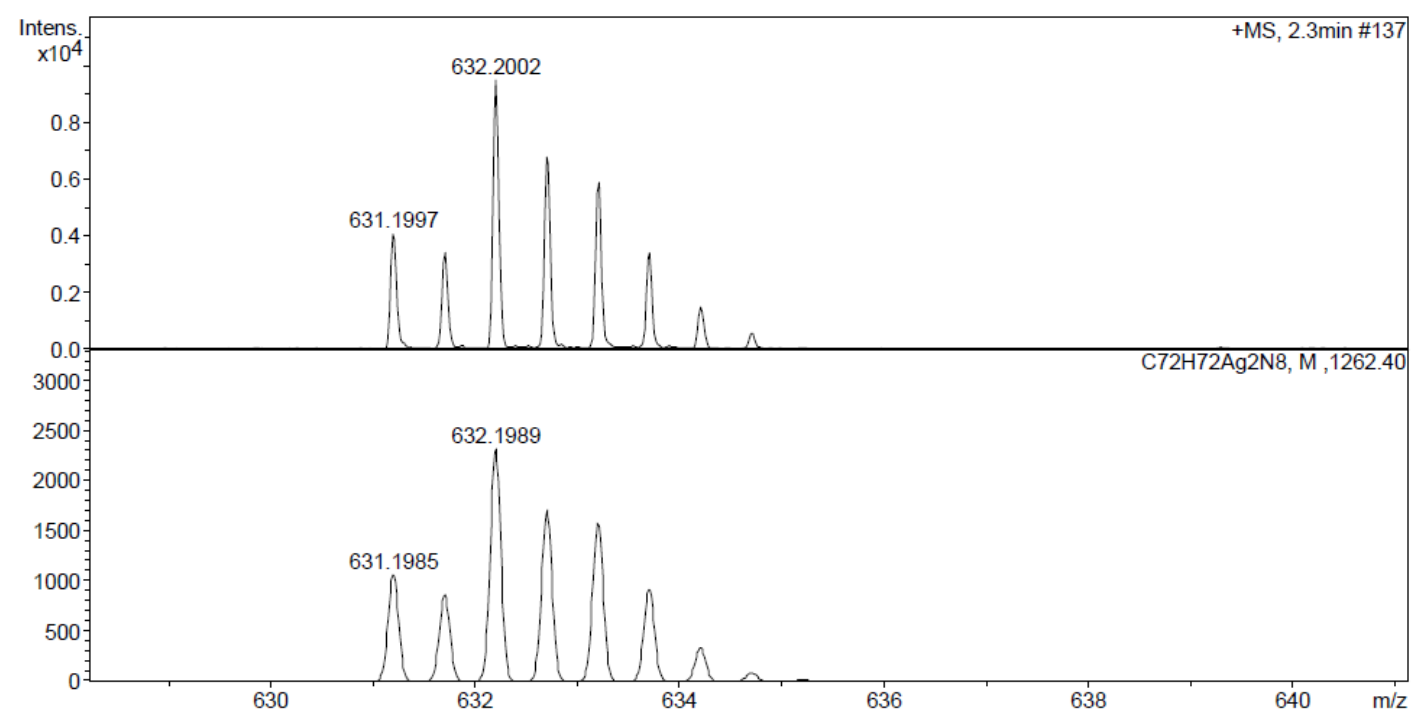

ESI-MS (positive ions) for $\left[\operatorname{Ag}_{2}(4)\right]^{2+}:$ Top (tested) and bottom (Calcd)

Figure S31. ESI-MS spectrum of $\left[\mathrm{Ag}_{2}(4)\right]\left(\mathrm{PF}_{6}\right)_{2}$ 


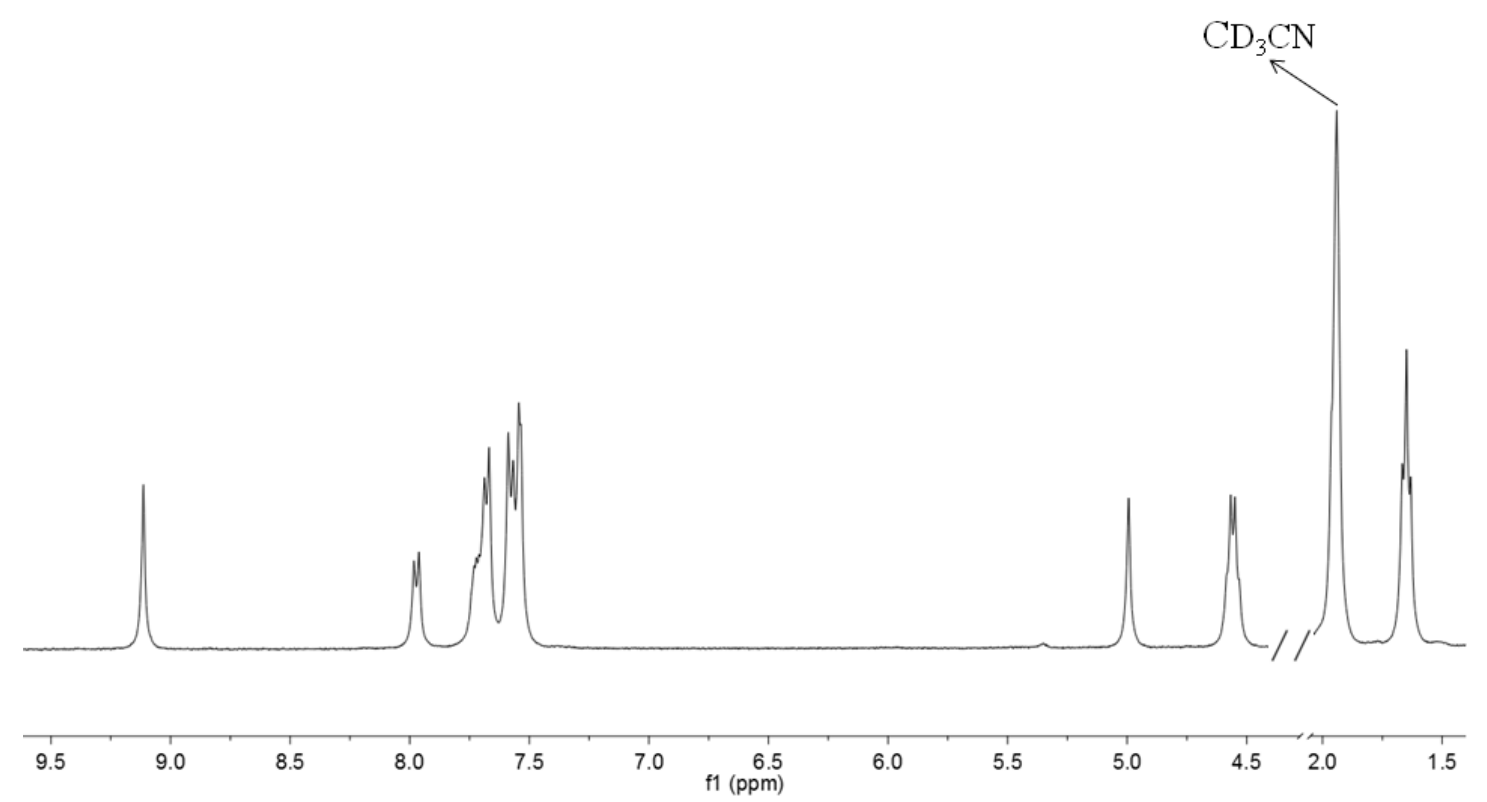

Figure S32. ${ }^{1} \mathrm{H}$ NMR $\left(400 \mathrm{MHz}, \mathrm{CD}_{3} \mathrm{CN}\right)$ of $\mathrm{H}_{4}-(3)\left(\mathrm{PF}_{6}\right)_{4}$

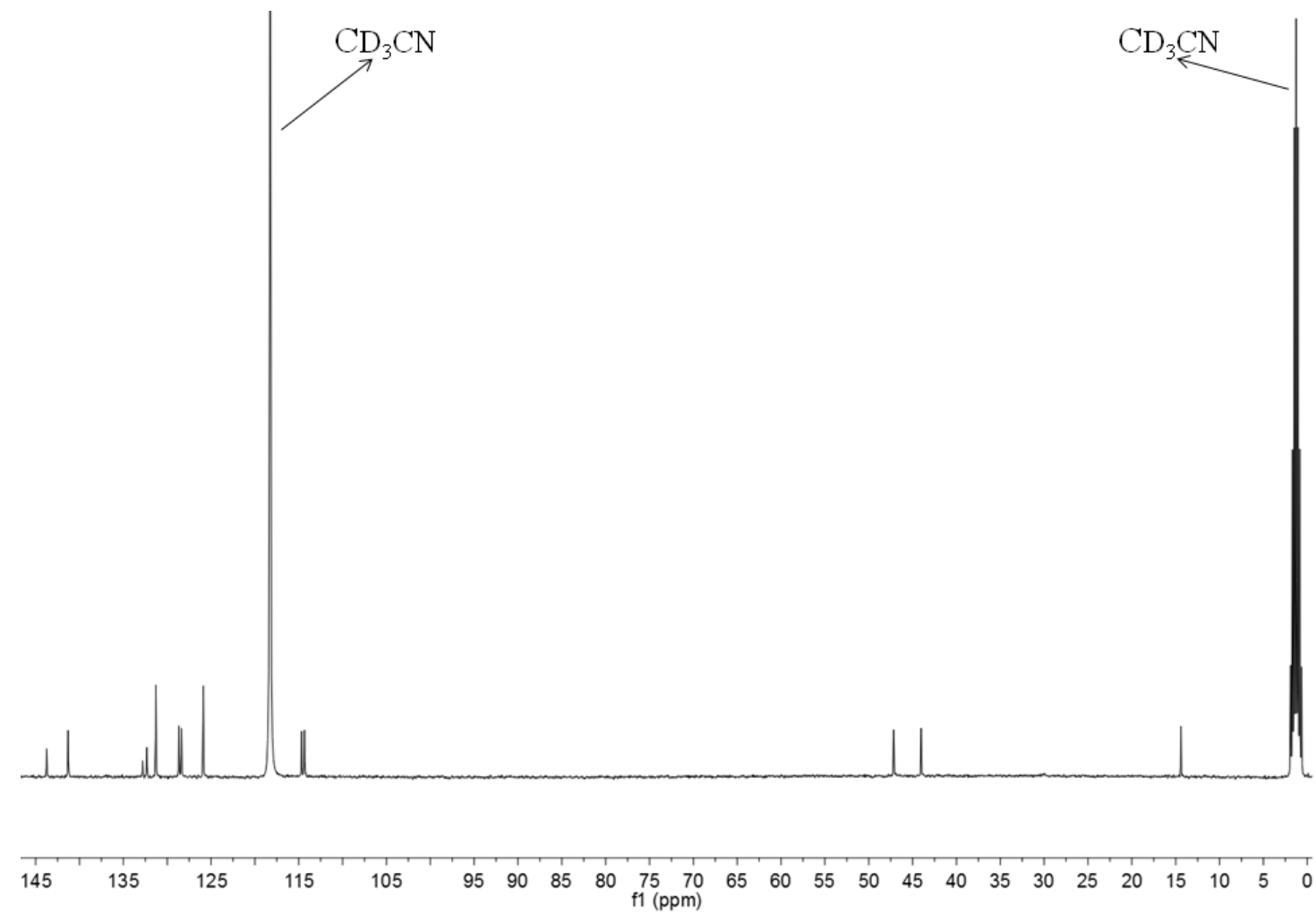

Figure S33. ${ }^{13} \mathrm{C}$ NMR $\left(100 \mathrm{MHz}, \mathrm{CD}_{3} \mathrm{CN}\right)$ of $\mathrm{H}_{4}-(3)\left(\mathrm{PF}_{6}\right)_{4}$ 


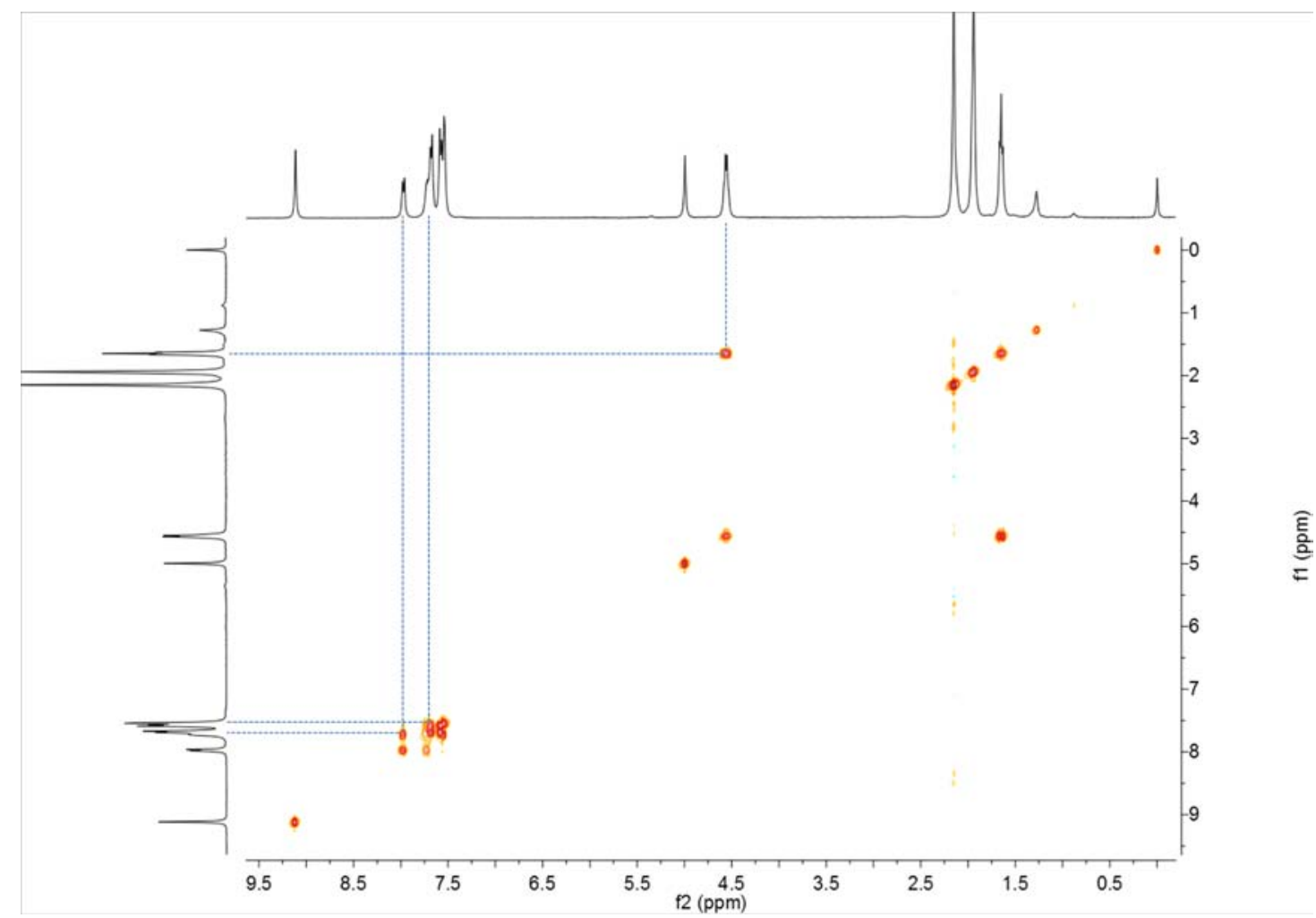

Figure S34. $\mathrm{HH}-\mathrm{COSY}\left(\mathrm{CD}_{3} \mathrm{CN}\right)$ of $\mathrm{H}_{4}-(3)\left(\mathrm{PF}_{6}\right)_{4}$

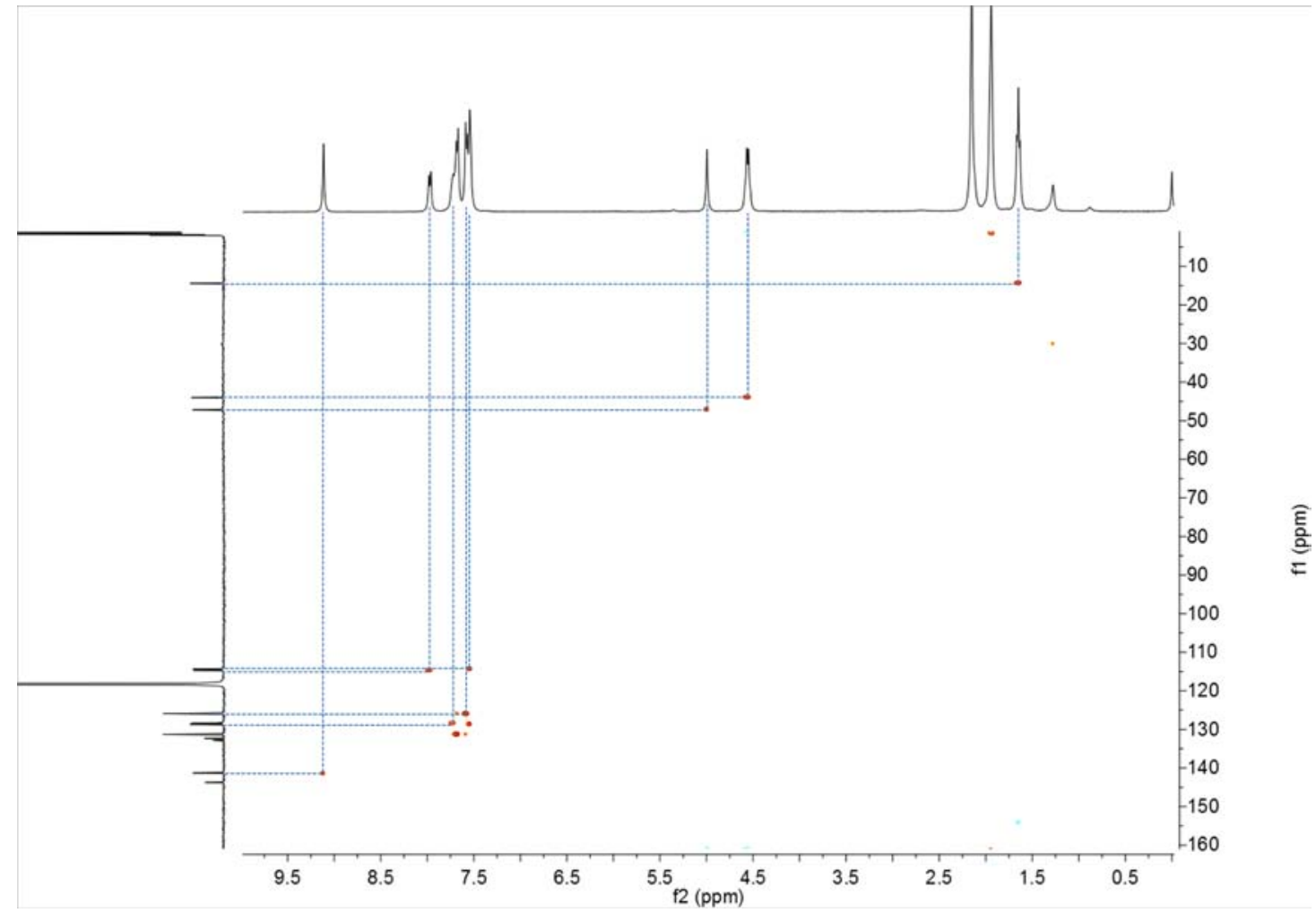

Figure S35. HC-HSQC $\left(\mathrm{CD}_{3} \mathrm{CN}\right)$ of $\mathrm{H}_{4}-(3)\left(\mathrm{PF}_{6}\right)_{4}$ 


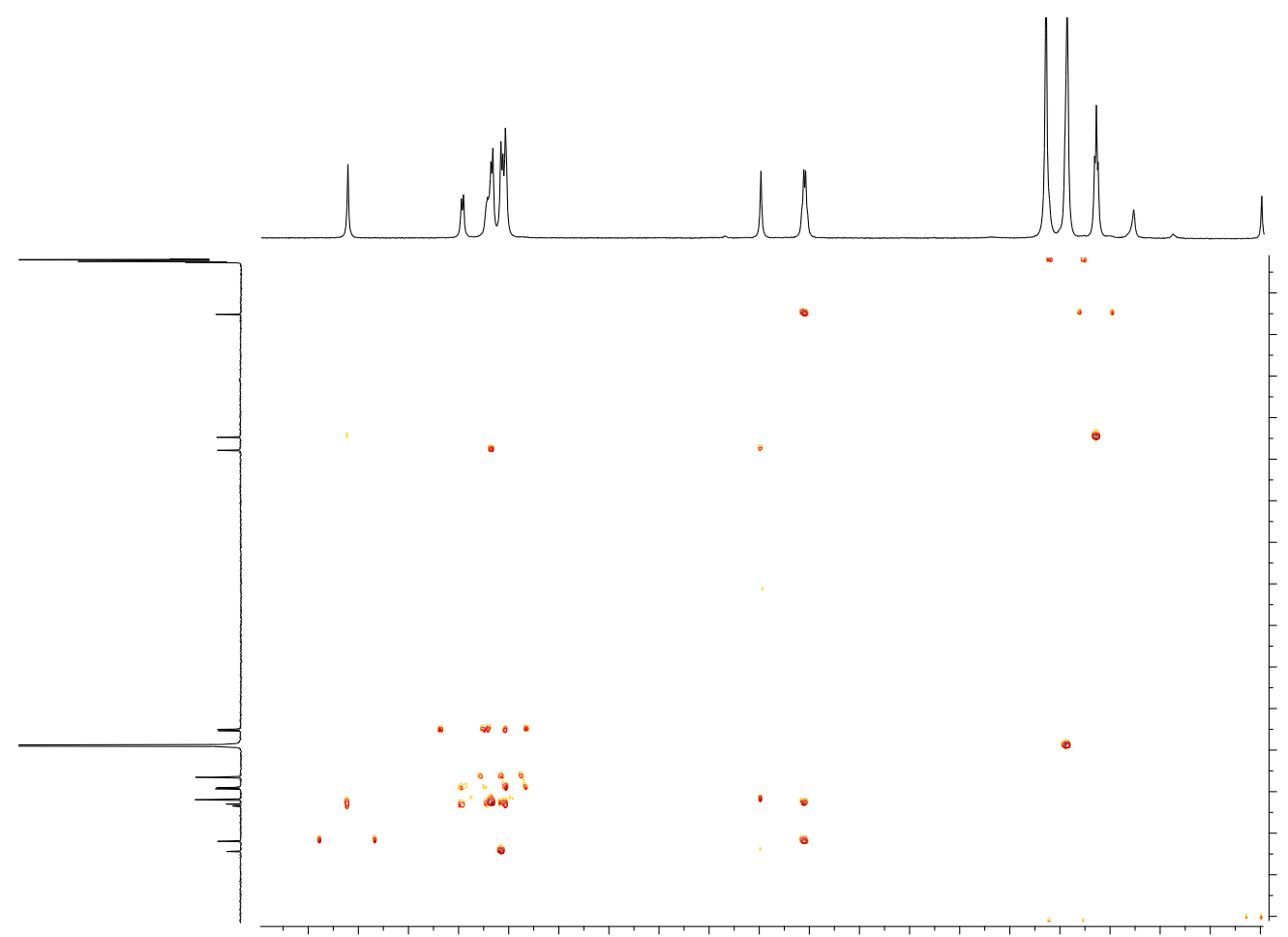

Figure S36. HC-HMQC $\left(\mathrm{CD}_{3} \mathrm{CN}\right)$ of $\mathrm{H}_{4}-(3)\left(\mathrm{PF}_{6}\right)_{4}$

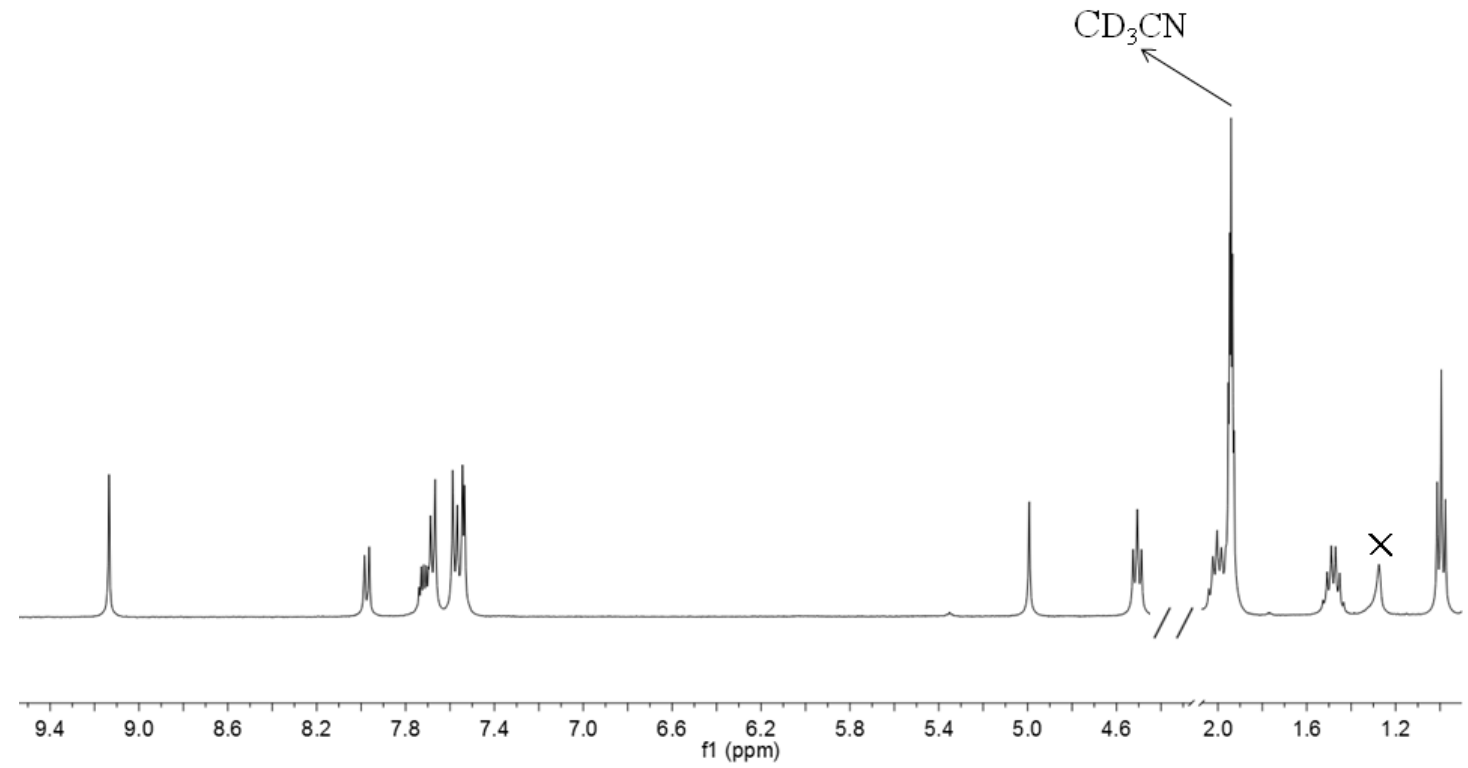

Figure S37. ${ }^{1} \mathrm{H}$ NMR (400 MHz, $\left.\mathrm{CD}_{3} \mathrm{CN}\right)$ of $\mathrm{H}_{4}-(4)\left(\mathrm{PF}_{6}\right)_{4}$ 


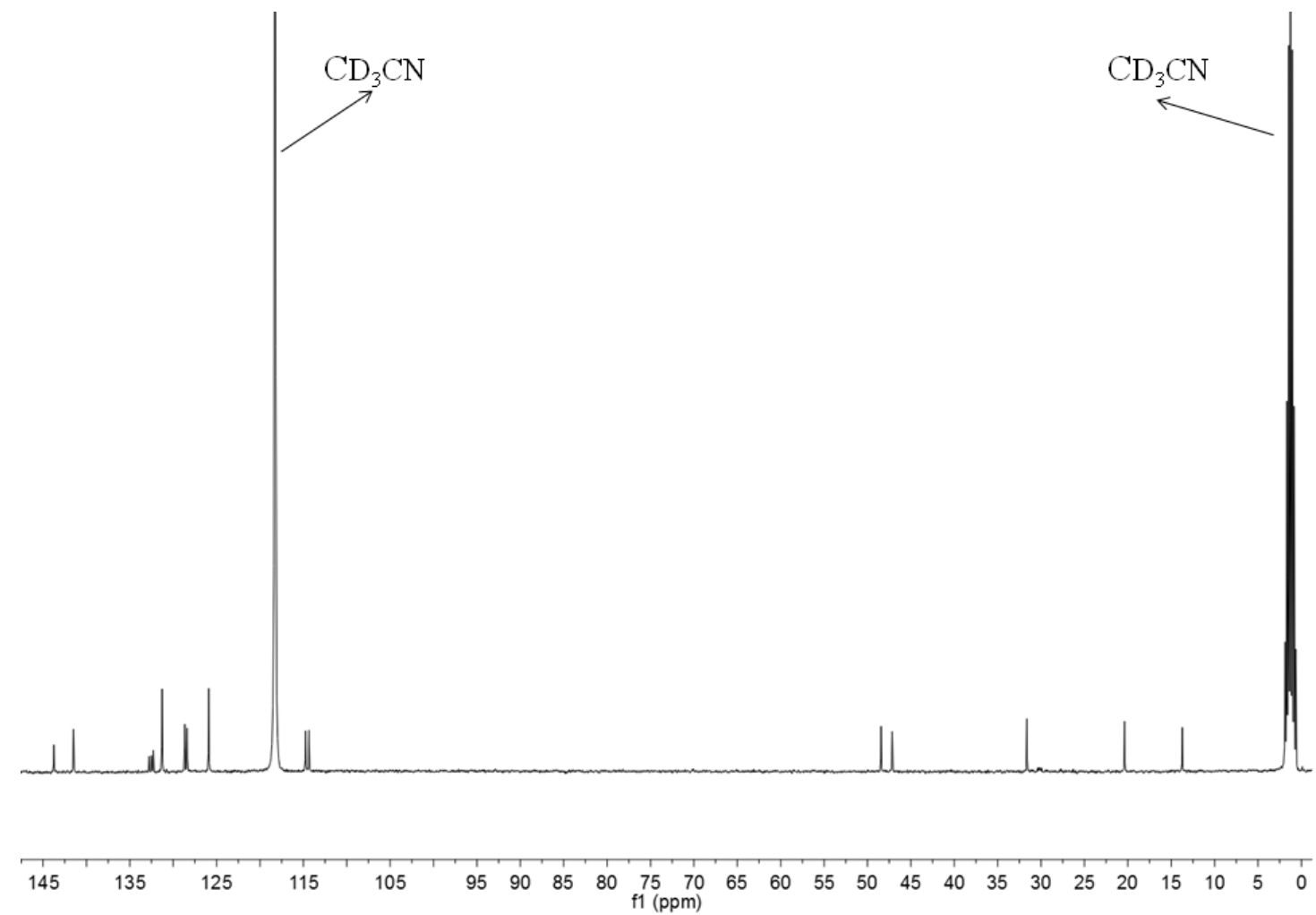

Figure S38. ${ }^{13} \mathrm{C}$ NMR $\left(100 \mathrm{MHz}, \mathrm{CD}_{3} \mathrm{CN}\right)$ of $\mathrm{H}_{4}-(4)\left(\mathrm{PF}_{6}\right)_{4}$

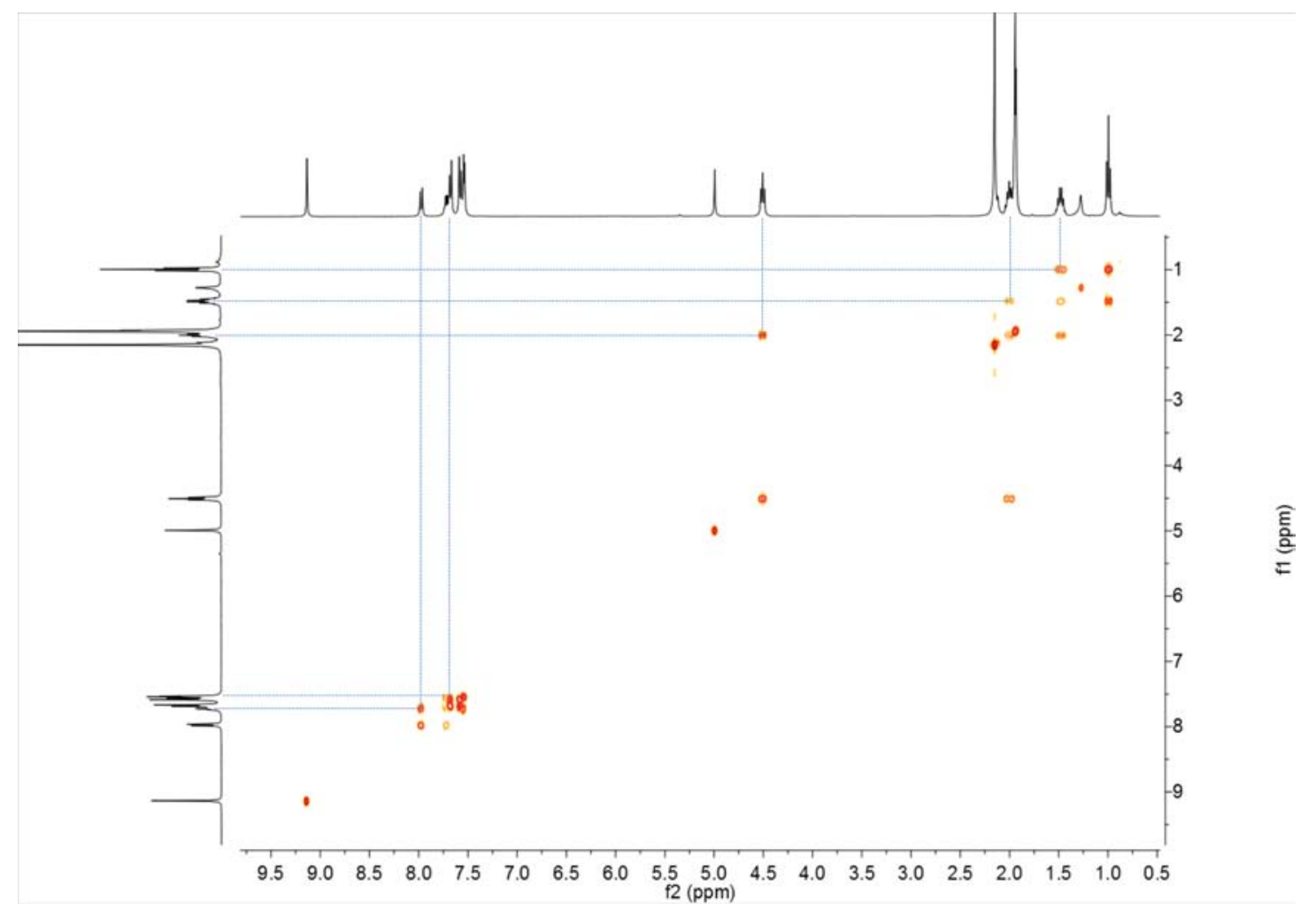

Figure S39. $\mathrm{HH}-\mathrm{COSY}\left(\mathrm{CD}_{3} \mathrm{CN}\right)$ of $\mathrm{H}_{4}-(4)\left(\mathrm{PF}_{6}\right)_{4}$ 


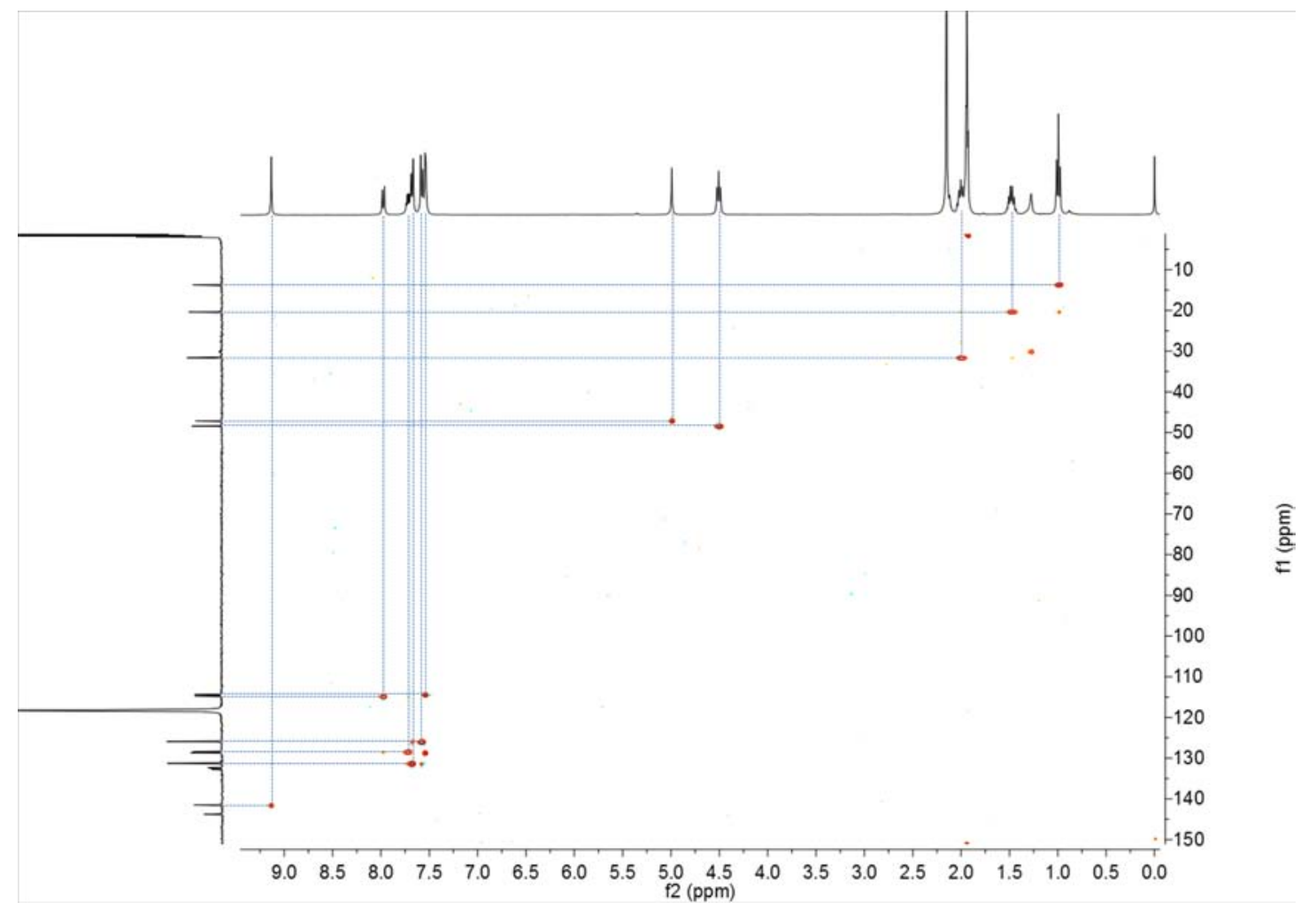

Figure S40. HC-HSQC $\left(\mathrm{CD}_{3} \mathrm{CN}\right)$ of $\mathrm{H}_{4}-(4)\left(\mathrm{PF}_{6}\right)_{4}$

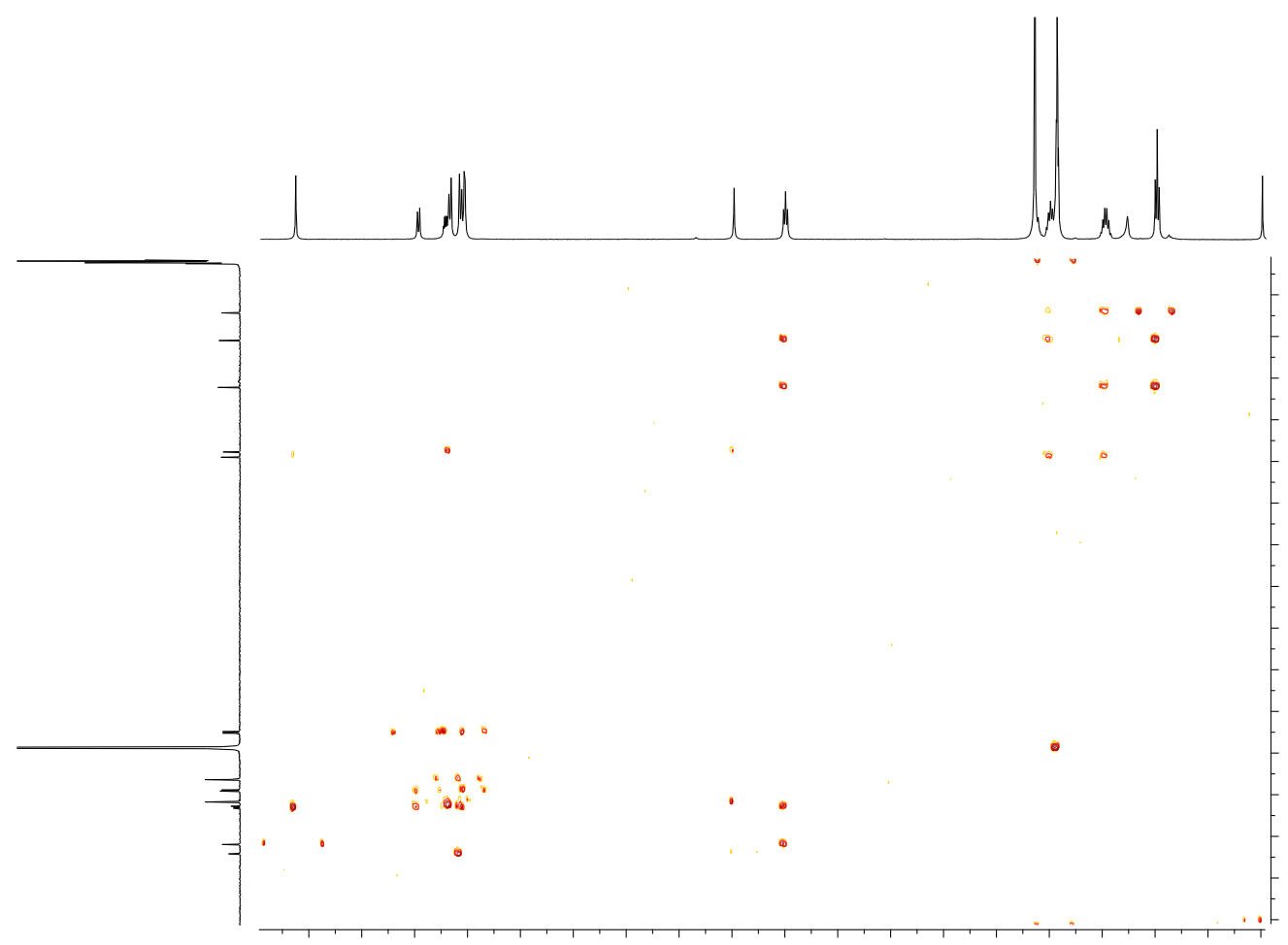

Figure S41. HC-HMQC $\left(\mathrm{CD}_{3} \mathrm{CN}\right)$ of $\mathrm{H}_{4}-(4)\left(\mathrm{PF}_{6}\right)_{4}$ 


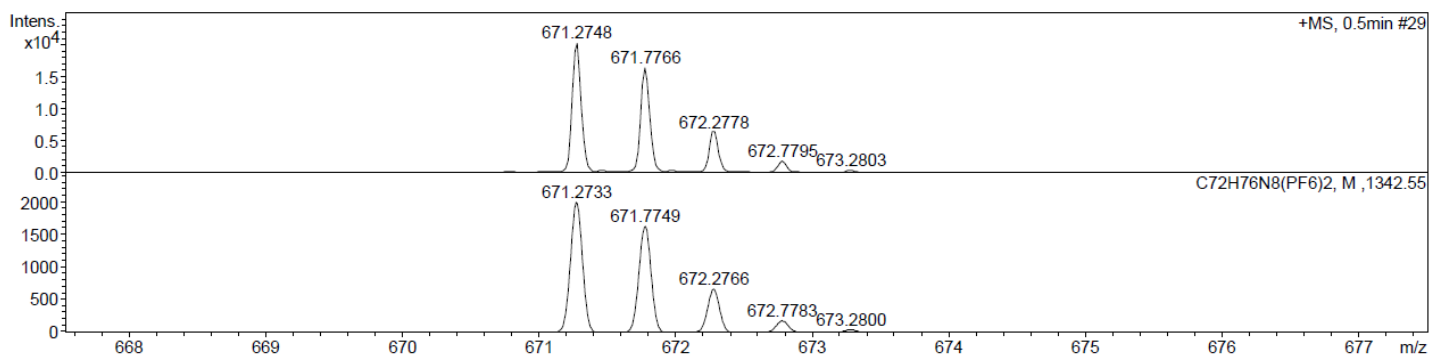

ESI-MS (positive ions) for $\left\{\mathrm{H}_{4}-\mathbf{4}\left(\mathrm{PF}_{6}\right)_{2}\right\}^{2+}$ : Top (tested) and bottom (Calcd)

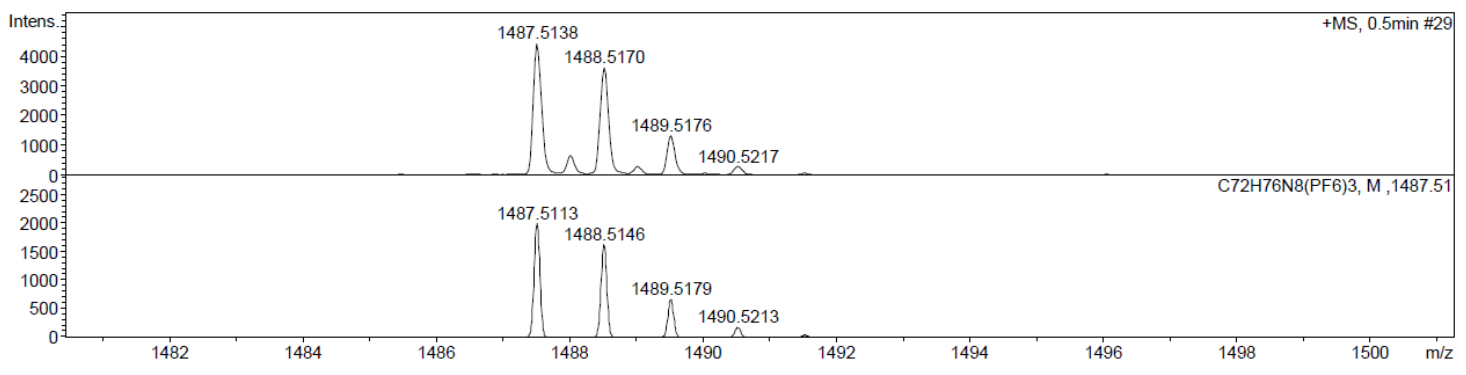

ESI-MS (positive ions) for $\left\{\mathrm{H}_{4}-\mathbf{4}\left(\mathrm{PF}_{6}\right)_{3}\right\}^{+}$: Top (tested) and bottom (Calcd)

Figure S42. ESI-MS spectra of $\mathrm{H}_{4}-(4)\left(\mathrm{PF}_{6}\right)_{4}$ 


\section{Crystal data:}

$\left[\mathrm{Ag}_{2}(4)\right]\left(\mathrm{PF}_{6}\right)\left(\mathrm{BF}_{4}\right) \cdot \mathrm{CH}_{3} \mathrm{CN}$ : Crystals suitable for an X-ray diffraction study were obtained by diffusion of diethyl ether into a acetonitrile solution of $\left[\mathrm{Ag}_{2}(4)\right]\left(\mathrm{PF}_{6}\right)_{2}$ in the presence of $\mathrm{NaBF}_{4} \cdot \mathrm{C}_{74} \mathrm{H}_{75} \mathrm{Ag}_{2} \mathrm{BF}_{10} \mathrm{~N}_{9} \mathrm{P}, M=1537.95$, colorless crystal, $0.24 \mathrm{x}$ $0.18 \times 0.04 \mathrm{~mm}^{3}$, triclinic, space group $P-1, Z=2, a=11.8068(13), b=15.4203(16)$, $c=21.207(2) \AA, \alpha=83.216(2)^{\circ}, \beta=75.227(2)^{\circ}, \gamma=73.672(2)^{\circ}, V=3578.3(7) \AA^{3}$, $\rho_{\text {calc }}=1.427 \mathrm{~g} \cdot \mathrm{cm}^{-3}, \mu=0.644 \mathrm{~mm}^{-1}, \omega$ - and $\varphi$-scans, 23523 measured intensities $\left(1.9^{\circ} \leq 2 \theta \leq 60.0^{\circ}\right)$, MoK $\alpha$ radiation, $\lambda=0.71073 \AA$, 13859 independent $\left(R_{\text {int }}=\right.$ 0.0369), refinement of 901 parameters against $\left|F^{2}\right|$ of all measured intensities with hydrogen atoms on calculated positions. $R=0.0779, w R=0.2255, R_{\text {all }}=0.1340, w R_{\text {all }}$ $=0.2850$.

$\mathrm{H}_{4}-3\left(\mathrm{PF}_{6}\right)_{4}$ : Crystals suitable for an X-ray diffraction study were obtained by diffusion of diethyl ether into a acetonitrile solution of $\left[\mathrm{H}_{4}-(3)\right]\left(\mathrm{PF}_{6}\right)_{4}$. $\mathrm{C}_{68} \mathrm{H}_{66} \mathrm{~F}_{24} \mathrm{~N}_{10} \mathrm{P}_{4}, M=1603.18, \mathrm{~T}=293(2) \mathrm{K}$, colorless crystal, $0.12 \times 0.10 \times 0.02$ $\mathrm{mm}^{3}$, triclinic, space group $P-1, Z=1, a=11.0245(4), b=12.2969(6), c=15.1731(6)$ $\AA, \alpha=79.298(4)^{\circ}, \beta=72.394(3)^{\circ}, \gamma=65.183(4)^{\circ}, V=1775.46(15) \AA^{3}, \rho_{\text {calc }}=1.499$ $\mathrm{g} \cdot \mathrm{cm}^{-3}, \mu=1.992 \mathrm{~mm}^{-1}, \omega$ - and $\varphi$-scans, 6462 measured intensities $\left(3.97^{\circ} \leq 2 \theta \leq\right.$ $\left.67.992^{\circ}\right), \lambda=1.54184 \AA, 6462$ independent $\left(R_{\mathrm{int}}=0.0409\right)$, refinement of 368 parameters against $\left|F^{2}\right|$ of all measured intensities with hydrogen atoms on calculated positions. $R=0.0772, w R=0.2201, R_{\text {all }}=0.0960, w R_{\text {all }}=0.2378$. 